\title{
Continuum Model Validation of Gas Jet Plume Injection into a Gas-Solid Bubbling Fluidized Bed
}

\author{
Deepak Rangarajan and Jennifer S. Curtis \\ Dept. of Chemical Engineering, University of Florida, Gainesville, FL 32611 \\ Sofiane Benyahia \\ National Energy Technology Laboratory, Morgantown, WV 26505 \\ Alexander G. Mychkovsky \\ Dept. of Mechanical Engineering, University of Michigan, Ann Arbor, MI 48109 \\ DOI 10.1002/aic.14018 \\ Published online January 31, 2013 in Wiley Online Library (wileyonlinelibrary.com)
}

\begin{abstract}
A continuum gas-solid model that includes descriptions for solid frictional stress and a turbulent gas phase is evaluated against published experimental measurements of mean and fluctuating velocity inside the jet plume region of a bubbling fluidized bed with a high-speed vertical jet injection. The main uncertainties in closure relations necessary in the continuum model are first identified and then determined using available experimental data. The overall model shows good agreement with both the gas and particle experimental velocity profiles. The trends in the centerline mean and fluctuating velocity with change in the fluidized state of the emulsion are also captured favorably. Main deviations between the model and experiment are noted and possible reasons for the mismatch are discussed. (C) 2013 American Institute of Chemical Engineers AIChE J, 59: 3247-3264, 2013
\end{abstract}

Keywords: multiphase flows for interphase exchanges, Eulerian-Eulerian modeling, continuum gas-solid modeling

\section{Introduction}

A bubbling fluidized bed with high-speed jet injection is commonly encountered in the gasification of coal or biomass. The bubbling emulsion action and the jet plume (void region close to the jet orifice) formation produces good contacting between the particles and gas medium resulting in favorable mixing properties. Predicting bubbling bed flows with high-speed jet injection is, therefore, essential for better understanding and design of gasifiers as well as many more industrial processes. Descriptions for such flows can be divided into two categories-semiempirical methods and hydrodynamic/computational modeling. In semiempirical methods, correlations are derived for engineering properties such as jet penetration length and shape as a function of operating conditions. ${ }^{1,2}$ Empirical correlations do not provide all the information necessary to understand the flow in detail and are susceptible to scale-up issues since they make macroscopic assumptions. On the other hand, continuum or two-fluid modeling involves solving differential equations which are based on first principles. It predicts complete flow behavior of the full-scale system, including microscopic details, making it more versatile and economically suitable. ${ }^{3}$ In continuum modeling, the particles are assumed to form a continuous fluid-like phase, and constitutive relations are

Correspondence concerning this article should be addressed to D. Rangarajan at deepakrangarajan@ufl.edu.

(C) 2013 American Institute of Chemical Engineers developed to close the continuum equations. However, appropriate description of these closure relations is a major challenge with continuum modeling.

The closure models required in the continuum framework are solid-phase kinetic and collisional stress, solid-phase frictional stress, gas-phase stress, and gas-solid drag. Further, if the gas phase is turbulent, a two-phase turbulence model that accounts for fluctuating energy transfer between the two phases is also required. An overview of closure model descriptions that have been used in the continuum framework can be found in Curtis and van Wachem, ${ }^{3}$ van Wachem and Almstedt, ${ }^{4}$ and van Wachem et al. ${ }^{5}$ Closure models can be characterized as well-established if they have been successfully tested over a wide range of flow conditions and applications. As will be noted when describing the continuum model later in this article, while the descriptions for solid-phase kinetic and collisional stress, gas-phase stress, and gas-solid drag can be considered fairly well-established, the main uncertainties lie in the descriptions for solid-phase frictional stress, and turbulence interaction. In predominantly dense flows $\left(\varepsilon_{\mathrm{s}}>20 \%\right)$ the gas-phase turbulence may be neglected and in relatively dilute flows $\left(\varepsilon_{\mathrm{s}}<50 \%\right)$ the frictional contribution to solid stress can be neglected. However, in bubbling flows with a high-speed jet injection, the solid volume fraction ranges from less than $1 \%$ in the jet plume region to close to maximum packing in the dense emulsion region, hence both these closures are significant in accurately predicting the flow details (Figure 1).

Since continuum modeling fundamentally assumes that particles behave like a continuous fluid phase and 

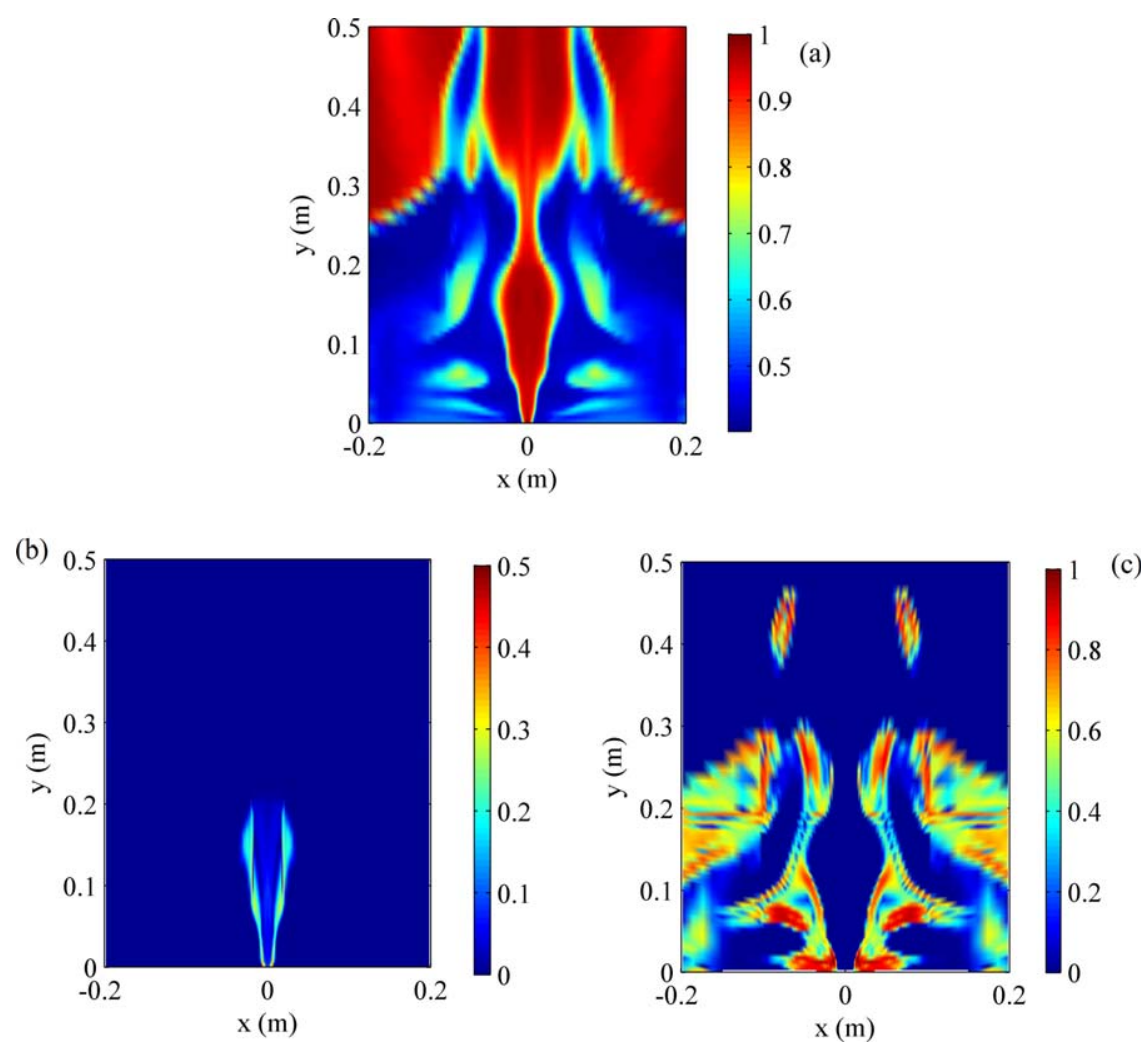

Figure 1. The significance of turbulent and frictional, stresses relative to drag, in a bubbling fluidized bed with a jet injection.

The simulation conditions are for $V_{j}=92 \mathrm{~m} / \mathrm{s}$ and $V_{f l}=1.5 V_{m f}$ at $t=15 \mathrm{~s}$. The continuum model used is the same as the final model developed in this article. (a) Gas volume fraction, (b) turbulent stress/(turbulent stress+drag), and (c) frictional stress/(frictional stress+drag). [Color figure can be viewed in the online issue, which is available at wileyonlinelibrary.com.]

encompasses some empiricism in closure relations, validating model predictions against experimental measurements is crucial in identifying the detail to which continuum modeling can be successfully applied. Validation studies involving continuum modeling of gas-solid bubbling bed flows have been conducted by numerous authors as discussed below.

Bubbling bed flows can be generally classified as uniformly fluidized beds and jet injection studies. Continuum modeling of bubbles formed in uniform fluidized beds compare model predictions and experimental measurements of bubble size, bubble shape, bed expansion, bubble rise velocity, solids distribution, and bed dynamics. ${ }^{5-9}$ Experimental data are typically obtained from a variety of imaging techniques such as radioactive particle tracking, optical probe, and electrical capacitance tomography. Validation studies involving jet injection into a packed bed have been mostly spouted bed studies. ${ }^{10-16}$ These compare fountain height, spout diameter, and minimum spouting velocity using data from digital camera and pressure transducer. ${ }^{10,11}$ More detailed evaluations of solids concentration, particle velocity, and granular temperature profiles have been made inside the spout region with the help of experimental data obtained from optical fiber probe and particle image velocimetry (PIV) techniques. ${ }^{12-17}$ However, no comparisons were made against gas velocity profiles. In the case of jet injection into a fluidized bed leading to a single bubble formation, comparisons between model and experiments have been made for bubble size and shape ${ }^{5}$ and also time-averaged porosity distribution as new bubbles form and rise continuously. ${ }^{18,19}$ The experi- mental data used for validation come from high-speed camera and optical probe measurements made for a jet injection velocity of $10 \mathrm{~m} / \mathrm{s}$ and at minimum fluidization conditions. In the case of jet injection leading to spout formation in fluidized beds (referred to as a jet plume in this article), the vector plot of particle movement near the spout and areaaveraged particle flux have been validated against experimental PIV measurements by Zhonghua and Mujumdar. ${ }^{14}$ In their study, a jet velocity of $20 \mathrm{~m} / \mathrm{s}$ was considered at a fluidization ratio of 1.5 times the minimum fluidization velocity. While most studies concerning jet injection into a fluidized bed deal with relatively low jet velocities (less than $20 \mathrm{~m} / \mathrm{s}$ ) where the turbulence in the gas phase is typically suppressed by particles, a few continuum modeling studies of high-speed jet injection can be found in literature. ${ }^{20-22}$ Horizontal jets of velocity up to $250 \mathrm{~m} / \mathrm{s}$ injected into a fluidized bed were modeled and evaluations were made only against macroscopic properties of jet penetration length and expansion angle. ${ }^{20,21}$ A more detailed continuum model validation of high-speed jet injection into a fluidized bed was conducted by Ettehadieh et al. ${ }^{22}$ A vertical jet of velocity 90 $\mathrm{m} / \mathrm{s}$ injected into a fluidized bed operated at minimum fluidization velocity was compared against mean gas and particle velocity, and solids fraction, obtained using pressure measurements and high-speed movies. However, no comparisons in the fluctuating velocities of either phase were made.

To summarize earlier validation studies, even the most detailed comparisons between experiment and continuum modeling of bubbling bed flows have been limited to mean 
velocity, mostly that of particles, and granular temperature profiles. Also, there are very few works that evaluate highspeed jet injection into a fluidized bed. In the present study, both gas and particle, mean and fluctuating velocity profiles inside a high-speed jet plume with varying fluidization levels are evaluated against the recent experimental work that used laser Doppler velocimetry (Rangarajan D, Mychkovsky AG, Curtis JS, Ceccio SL. Effect of emulsion fluidization state on the fluctuations in gas and particle velocities inside the plume of a gas jet penetrating a fluidized bed. Powder Technol. 2011; submitted). ${ }^{23}$ The experiments also provide the fluidization curve measured using a pressure gauge and digital videos of particle movement.

The aim of the present work is two-fold:

1. To determine appropriate closure relations that are necessary in a continuum model to describe bubbling beds with a high-speed jet injection, by conducting a series of test cases with increasing complexity.

2. Evaluate the bubbling bed continuum model predictions against two-phase experimental velocity measurements which have been made at a detailed level.

\section{Model Description}

\section{Governing equations}

The governing equations follow from the volume averaged equations of Anderson and Jackson ${ }^{24}$ applied to gas-solid flows. Continuity and momentum balance equations are solved for each phase as shown below.

$$
\begin{gathered}
\frac{\partial \varepsilon_{\mathrm{g}}}{\partial t}+\nabla \cdot\left(\varepsilon_{\mathrm{g}} \underline{u_{\mathrm{g}}}\right)=0 \\
\frac{\partial \varepsilon_{\mathrm{s}}}{\partial t}+\nabla \cdot\left(\varepsilon_{\mathrm{s}} \underline{u_{\mathrm{s}}}\right)=0 \\
\rho_{\mathrm{g}} \varepsilon_{\mathrm{g}}\left[\frac{\partial \underline{u_{\mathrm{g}}}}{\partial t}+\underline{u_{\mathrm{g}}} \cdot \nabla \underline{u_{\mathrm{g}}}\right]=-\varepsilon_{\mathrm{g}} \nabla p_{\mathrm{g}}++\nabla \cdot\left(\underline{\left.\varepsilon_{\mathrm{g}} \underline{\underline{\mathrm{g}}}\right)-\underline{F_{\mathrm{D}}}+\varepsilon_{\mathrm{g}} \rho_{\mathrm{g}} \underline{g}}\right. \\
\rho_{\mathrm{s}} \varepsilon_{\mathrm{s}}\left[\frac{\partial \underline{u_{\mathrm{s}}}}{\partial t}+\underline{u_{\mathrm{s}}} \cdot \nabla \underline{u_{\mathrm{s}}}\right]=-\varepsilon_{\mathrm{s}} \nabla p_{\mathrm{g}}++\nabla \underline{\underline{\sigma_{\mathrm{s}}}}+\underline{F_{\mathrm{D}}}+\varepsilon_{\mathrm{s}} \rho_{\mathrm{s}} \underline{g}
\end{gathered}
$$

Here, $t$ is time, $\varepsilon_{\mathrm{g}}$ is the gas volume fraction, $\varepsilon_{\mathrm{s}}$ is the solids volume fraction (note that the conservation of total volume requires an additional independent relation between volume fractions such that $\left.\varepsilon_{\mathrm{g}}+\varepsilon_{\mathrm{s}}=1\right), \underline{u}_{\mathrm{g}}$ is the gas mean velocity, $\underline{u}_{\mathrm{s}}$ is solids mean velocity, $\rho_{\mathrm{g}}$ is the gas density, $\rho_{\mathrm{s}}$ is the solids density, $p_{\mathrm{g}}$ is the gas pressure, and $\underline{g}$ is the acceleration due to gravity.

To close the above set of equations, constitutive relations are needed for the gas-phase stress, $\tau_{\mathrm{g}}$, drag force per unit volume, $\underline{F}_{D}$, and solid-phase stress, $\underline{\underline{\sigma}}_{\mathrm{s}}$. The solid-phase stress is further divided into two additive components, the kinetic and collisional component, $\underline{\underline{\sigma}}_{\mathrm{s}}^{k c}$, and the frictional component, $\underline{\underline{\sigma}}_{\mathrm{s}}^{f}$.

\section{Gas-solid drag}

Drag models represent the momentum transfer between the mean velocity components of both phases. The drag force per unit volume $\left(\underline{F}_{\mathrm{D}}\right)$ is given by

$$
\underline{F_{\mathrm{D}}}=\beta\left(\underline{u_{\mathrm{g}}}-\underline{u_{\mathrm{s}}}\right)
$$

Model development for the friction coefficient $\beta$ has been mainly semitheoretical in literature. Drag models contain physical parameters and have been tested over a wide range of flow regimes over the years. Though there are multiple expressions for friction coefficient in literature there is fairly good agreement on the Wen and $\mathrm{Yu}^{25}$ expression when dealing with fluidization flows. ${ }^{25-29}$ Therefore, the wellestablished Wen and $\mathrm{Yu}^{25}$ drag expression is used to close the gas-solid drag force in the present continuum model.

$$
\begin{gathered}
\beta=\frac{3}{4} C_{\mathrm{D}} \frac{\rho_{\mathrm{g}} \varepsilon_{\mathrm{g}} \varepsilon_{\mathrm{s}}\left|\underline{u_{\mathrm{g}}}-\underline{u_{\mathrm{s}}}\right|}{d_{\mathrm{p}}} \varepsilon_{\mathrm{g}}^{-2.65} \\
C_{\mathrm{D}}=\left\{\begin{array}{c}
\frac{24\left(1+0.15 \mathrm{Re}^{0.687}\right)}{\operatorname{Re}}, \operatorname{Re}<1000 \\
0.44, \operatorname{Re}>1000
\end{array}\right. \\
R e_{\mathrm{p}}=\frac{d_{\mathrm{p}} \varepsilon_{\mathrm{g}}\left|\underline{u_{\mathrm{g}}}-\underline{u_{\mathrm{s}}}\right|}{\mu_{\mathrm{g}}}
\end{gathered}
$$

where $d_{\mathrm{p}}=$ particle diameter, $C_{\mathrm{D}}=$ drag coefficient, and $\operatorname{Re}_{\mathrm{p}}=$ particle Reynolds number.

\section{Gas-phase stress}

To describe the turbulent gas phase, a standard high Reynolds number k-epsilon model modified to account for the presence of a particle phase is adopted. Such an approach has been successfully used in many turbulent twophase flows. ${ }^{12,29-31}$

$$
\begin{aligned}
& \rho_{\mathrm{g}} \varepsilon_{\mathrm{g}}\left[\frac{\partial k}{\partial t}+\underline{u_{\mathrm{g}}} \cdot \nabla k\right]=\nabla \cdot\left(\varepsilon_{\mathrm{g}} \frac{\mu_{\mathrm{g}}^{t}}{\sigma_{k}} \nabla k\right)+\varepsilon_{\mathrm{g}} \underline{\underline{\tau_{\mathrm{g}}}}: \nabla \underline{u_{\mathrm{g}}}-\varepsilon_{\mathrm{g}} \rho_{\mathrm{g}} \varepsilon+\pi_{k} \\
& \rho_{\mathrm{g}} \varepsilon_{\mathrm{g}}\left[\frac{\partial \varepsilon}{\partial t}+\underline{u_{\mathrm{g}}} \cdot \nabla \varepsilon\right]=\nabla \cdot\left(\varepsilon_{\mathrm{g}} \frac{\mu_{\mathrm{g}}^{t}}{\sigma_{\varepsilon}} \nabla \varepsilon\right) \\
& +\varepsilon_{\mathrm{g}} \frac{\varepsilon}{k}\left(C_{1 \varepsilon} \underline{\underline{\tau_{\mathrm{g}}}}: \nabla \underline{u_{\mathrm{g}}}-\rho_{\mathrm{g}} C_{2 \varepsilon} \varepsilon\right)+C_{3 \varepsilon} \frac{\varepsilon}{k} \pi_{k} \\
& \underline{\underline{\tau_{g}}}=\mu_{\mathrm{g}}^{e}\left[\nabla \underline{u_{\mathrm{g}}}+\nabla \underline{u_{\mathrm{g}}}{ }^{T}-\frac{2}{3}\left(\nabla \cdot \underline{u_{\mathrm{g}}}\right) \underline{I}\right] \\
& \mu_{\mathrm{g}}^{t}=\rho_{\mathrm{g}} C_{\mu} \frac{k^{2}}{\varepsilon} ; \quad \mu_{\mathrm{g}}^{e}=\mu_{\mathrm{g}}+\mu_{\mathrm{g}}^{t}
\end{aligned}
$$

Most terms in the above equations are analogous to the single-phase turbulence model. The $k$ and $\varepsilon$ equations represent the balance of convective and diffusive transport with the production and dissipation of turbulent kinetic energy and turbulent energy dissipation, respectively. The main change in the two-phase equations is in the presence of a turbulence modulation term, $\pi_{k}$. This term represents the enhancement or damping of turbulent kinetic energy due to the presence of a particle phase. The closure for this term is not well-established in literature and will be discussed in the turbulence interaction terms section. The model constants in the k-epsilon equations are specified to be $\sigma_{k}=1.0, \sigma_{\varepsilon}=1.3$, $C_{1 \varepsilon}=1.44, C_{2 \varepsilon}=1.92, C_{3 \varepsilon}=1.22$, and $C_{\mu}=0.09$.

\section{Solid-phase kinetic and collisional stress}

The stress experienced by the particles due to translation and instantaneous collisions is referred to as solid-phase kinetic and collisional stress $\left(\underline{\underline{\sigma}}_{\mathrm{s}}^{k c}\right)$. Kinetic and collisional stress depends on the magnitude of particle velocity fluctuations $\left(\underline{u}_{\mathrm{s}}^{\prime}\right)$, also called granular temperature, $\theta$. 


$$
\theta=\frac{1}{3}\left(\underline{\underline{u_{\mathrm{s}}^{\prime}} \cdot \underline{u_{\mathrm{s}}^{\prime}}}\right)
$$

Therefore, a granular energy balance is solved along with the other governing equations.

$$
\frac{3}{2} \rho_{\mathrm{s}} \varepsilon_{\mathrm{s}}\left[\frac{\partial \theta}{\partial t}+\underline{u_{\mathrm{s}}} \cdot \nabla \theta\right]=\nabla \cdot\left(\kappa_{\mathrm{s}} \nabla \theta\right)+\underline{\underline{\sigma_{\mathrm{s}}^{\mathrm{kc}}}}: \nabla \underline{u_{\mathrm{s}}}-\varepsilon_{\mathrm{s}} \rho_{\mathrm{s}} J_{\mathrm{s}}+\pi_{\theta}
$$

This balance generates three additional terms that require closure, namely, granular conductivity $\left(\kappa_{\mathrm{s}}\right)$, collisional dissipation $\left(J_{\mathrm{s}}\right)$, and the granular temperature modulation $\left(\pi_{k}\right)$. The solid-phase kinetic and collisional stress, granular conductivity, and collisional dissipation are expressed in terms of granular temperature, in a fashion analogous to the kinetic theory of gases but accounting for inelastic particle collisions and the fact that particles occupy space (Eqs. 15). These equations were theoretically derived by Lun et al. ${ }^{32}$ for spherical particles, with restitution coefficient $e$, in vacuum. A slightly modified version of Lun et al. ${ }^{32}$ proposed by Agrawal et al. ${ }^{33}$ that accounts for interstitial gas, is adopted to describe the solids viscosity and solids conductivity in the present study.

$$
\begin{aligned}
\underline{\underline{\sigma_{\mathrm{s}}^{\mathrm{kc}}}=} & \left(-p_{\mathrm{s}}^{\mathrm{kc}}+\eta \mu_{\mathrm{b}}^{\mathrm{kc}} \nabla \cdot \underline{u_{\mathrm{g}}}\right) \underline{I}=\mu_{\mathrm{s}}^{\mathrm{kc}}\left[\nabla \underline{u_{\mathrm{s}}}+\nabla \underline{u_{\mathrm{s}}^{\mathrm{T}}}-\frac{2}{3}\left(\nabla \cdot \underline{u_{\mathrm{s}}}\right)=\underline{I}=\right] \\
\mu_{\mathrm{s}}^{\mathrm{kc}}= & \left(\frac{2+\alpha}{3}\right)\left[\frac{\mu_{\mathrm{s}}^{\mathrm{kc} *}}{g_{0} \eta(2-\eta)}\left(1+\frac{8}{5} \eta \varepsilon_{\mathrm{s}} g_{0}\right)\right. \\
& \left.\times\left(1+\frac{8}{5} \eta(3 \eta-2) \varepsilon_{\mathrm{s}} g_{0}\right)+\frac{3}{5} \eta \mu_{\mathrm{b}}^{\mathrm{kc}}\right] ; \quad \alpha=1.5 \\
\mu_{\mathrm{s}}^{\mathrm{kc} *}= & \frac{\rho_{\mathrm{s}} \varepsilon_{\mathrm{s}} g_{0} \theta \mu^{\mathrm{kc}} \theta\left(1+4 \eta \varepsilon_{\mathrm{s}} g_{0}\right)}{\rho_{\mathrm{s}} \varepsilon_{\mathrm{s}} g_{0} \theta+\left(\frac{2 \beta \mu^{\mathrm{kc}}}{\rho_{\mathrm{s}} \varepsilon_{\mathrm{s}}}\right)} ; \quad \mu^{\mathrm{kc}}=\frac{5}{96} \rho_{\mathrm{s}} d_{\mathrm{p}} \sqrt{\pi \theta} ; \\
& \mu_{\mathrm{b}}^{\mathrm{kc}}=\frac{256}{5 \pi} \mu^{\mathrm{kc}} \varepsilon_{\mathrm{s}}^{2} g_{0} ; \quad \eta=(1+e) / 2 \\
\kappa_{\mathrm{s}}= & \left(\frac{\kappa_{\mathrm{s}}^{*}}{g_{0}}\right)\left[( 1 + \frac { 1 2 } { 5 } \eta \varepsilon _ { \mathrm { s } } g _ { 0 } ) \left(1+\frac{12}{5} \eta^{2}(4 \eta-3) \varepsilon_{\mathrm{s}} g_{0}\right.\right. \\
& \left.\left.+\frac{64}{25 \pi}(41-33 \eta) \eta^{2}\left(\varepsilon_{\mathrm{s}} g_{0}\right)^{2}\right)\right] \\
& \kappa_{\mathrm{s}}^{*}=\frac{\rho_{\mathrm{s}} \varepsilon_{\mathrm{s}} g_{0} \theta \kappa}{\rho_{\mathrm{s}} \varepsilon_{\mathrm{s}} g_{0} \theta+\left(\frac{6 \beta \kappa}{5 \rho_{\mathrm{s}} \varepsilon_{\mathrm{s}}}\right)}, \quad \kappa=\frac{75 \rho_{\mathrm{s}} d_{\mathrm{p}} \sqrt{\pi \theta}}{48 \eta(41-33 \eta)} \\
J_{\mathrm{s}}=\frac{48}{\pi} \eta(1-\eta) & \varepsilon_{\mathrm{s}} g_{0} \theta^{3 / 2}
\end{aligned}
$$

The above equations, also referred to as granular kinetic theory, have been applied in gas-solid flows successfully over dilute ${ }^{29,33}$ and dense regimes, ${ }^{13,21,26,34}$ and there is generally good agreement in literature. The radial distribution function at contact $\left(g_{0}\right)$ is expressed using the equation of Carnahan and Starling ${ }^{35}$ in the present study.

$$
g_{0}=\frac{1-0.5 \varepsilon_{\mathrm{s}}}{\left(1-\varepsilon_{\mathrm{s}}\right)^{3}}
$$

The closure for the interaction term, $\pi_{\theta}$, will be described in the turbulence interaction term section.

\section{Solid-phase frictional stress}

In the emulsion region of flow where solids volume fractions are high, an appropriate description of stress that accounts for the sustained contacts between particles is necessary while describing solid-phase stress. This stress, termed as frictional stress $\left(\underline{\underline{\sigma}}_{\mathrm{s}}^{f}\right)$, is typically written in Newtonian form and added to the stress predicted by the granular kinetic theory, which assumes instantaneous collisions.

$$
\begin{gathered}
\underline{\underline{\sigma_{\mathrm{s}}^{\mathrm{f}}}=-p_{\mathrm{s}}^{\mathrm{f}} \underline{\underline{I}}+\mu_{\mathrm{s}}^{\mathrm{f}}\left(\nabla \underline{u_{\mathrm{s}}}+\nabla \underline{u_{\mathrm{s}}}\right)} \\
\underline{\underline{\sigma_{\mathrm{s}}}}=\underline{\underline{\sigma_{\mathrm{s}}^{\mathrm{kc}}}}+\underline{\underline{\sigma_{\mathrm{s}}^{\mathrm{f}}}}
\end{gathered}
$$

Empirical theories derived from soil mechanics concepts have been traditionally used to model the frictional pressure $\left(p_{\mathrm{s}}^{\mathrm{f}}\right)$ and viscosity $\left(\mu_{\mathrm{s}}^{\mathrm{f}}\right)$ terms in the above equation. Numerous friction model validation studies ${ }^{8,19,26,36-38}$ can be found in literature ranging from simple flows such as bin discharge ${ }^{26,36}$ to more complex bubbling bed flows. ${ }^{37}$ Frictional models contain many empirical constants and there is no consensus on the best form of frictional stress yet.

Two commonly used expressions for frictional pressure come from Syamlal et al. ${ }^{39}$ and Johnson et al. ${ }^{40}$ The Syamlal et al. $^{41}$ expression is a power law function of solids volume fraction that is activated only when the solids volume fraction exceeds the maximum packing limit. Numerous authors have recognized the deficiency of this model which predicts no frictional stress below the packing limit. ${ }^{36,38}$ Therefore, in the present article, a widely accepted form of frictional pressure based on Johnson et al. ${ }^{40}$ is used and the granular assembly is assumed to deform without any volume change (critical state).

$$
p_{\mathrm{s}}^{\mathrm{f}}=\left\{\begin{array}{l}
10^{25}\left(\varepsilon_{\mathrm{s}}-\varepsilon_{\mathrm{s}}^{\max }\right)^{10}, \quad \varepsilon_{\mathrm{s}}>\varepsilon_{\mathrm{s}}^{\max } \\
\operatorname{Fr} \frac{\left(\varepsilon_{\mathrm{s}}-\varepsilon_{\mathrm{s}}^{\min }\right)^{r}}{\left(\varepsilon_{\mathrm{s}}^{\max }-\varepsilon_{\mathrm{s}}\right)^{s}}, \quad \varepsilon_{\mathrm{s}}^{\max } \geq \varepsilon_{\mathrm{s}}>\varepsilon_{\mathrm{s}}^{\min } \\
0, \quad \varepsilon_{\mathrm{s}} \leq \varepsilon_{\mathrm{s}}^{\min }
\end{array}\right.
$$

However, the above expression contains material-dependent empirical constants, $F r, r, s$, and $\varepsilon_{\mathrm{s}}{ }^{\mathrm{min}}$ which need to be determined. Following the arguments of Johnson et al., ${ }^{40}$ the values of $r=2$, and $s=5$ are chosen such that frictional pressure increases very rapidly as $\varepsilon_{\mathrm{s}}$ approaches $\varepsilon_{\mathrm{s}}$ max and $\varepsilon_{\mathrm{s}}^{\mathrm{min}}=0.5$ is chosen so that frictional forces vanish when the solids volume is below $50 \%$. Johnson et al. ${ }^{40}$ chose the multiplier, $F r$, to match the material's random packing fraction and studied flow down an inclined chute. However, a more appropriate calibration for $F r$ is necessary for fluidized bed flows, as is attempted in the present article.

Frictional viscosity has been traditionally modeled from approaches of Schaeffer, ${ }^{41}$ Savage, ${ }^{42}$ and Srivastava and Sundaresan. ${ }^{26}$ All the three approaches are largely based on soil mechanics and assume that frictional viscosity is directly proportional to the normal stress or frictional pressure. Savage $^{42}$ model assumes that frictional viscosity decreases with increase in fluctuations in the solid strain rate, whereas the Schaeffer ${ }^{41}$ model assumes that frictional viscosity decreases with increase in the mean strain rate. The Srivastava and Sundaresan $^{26}$ model is an ad-hoc combination of the other two models. Since different authors have used different approaches successfully, a comparative study with experiment is necessary to determine the frictional viscosity model most suitable for the present application. 
Table 1. Comparison of Closure Models Between MFIX and Present Study

\begin{tabular}{|c|c|c|c|}
\hline Closure & Term & MFIX Default & Present Study \\
\hline Drag & Drag coefficient & Syamlal et al. ${ }^{39}$ & Wen and $\mathrm{Yu}^{25}$ \\
\hline \multirow[t]{3}{*}{$\begin{array}{l}\text { Solid-phase kinetic and } \\
\text { collisional stress }\end{array}$} & $\begin{array}{l}\text { Pressure, viscosity, and granular } \\
\text { conductivity }\end{array}$ & Agrawal et al. ${ }^{33}$ & Same \\
\hline & Collisional dissipation & Lun et al. ${ }^{32}$ & Same \\
\hline & Radial distribution function & Carnahan and Starling ${ }^{35}$ & Same \\
\hline \multirow[t]{2}{*}{ Solid-phase frictional stress } & Frictional pressure & Syamlal et al. ${ }^{39}$ & $\begin{array}{c}\text { Johnson et al. }{ }^{40}(r=2, s=5 \text { and } \\
\left.\varepsilon_{\mathrm{s}}{ }^{\operatorname{lin}}=0.5\right) F r \text { TBD }\end{array}$ \\
\hline & Frictional viscosity & Schaeffer ${ }^{41}$ & TBD \\
\hline Gas-phase stress & Turbulent viscosity & Standard k-epsilon & Same \\
\hline Gas-particle turbulence & Gas turbulence modulation & 0 & TBD \\
\hline interaction & Granular temperature modulation & Agrawal et al. ${ }^{33}$ & Same \\
\hline
\end{tabular}

\section{Turbulence interaction}

The interphase interaction terms seen in the granular energy equation and the turbulent kinetic energy equation, $\pi_{\theta}$ and $\pi_{k}$, represent the energy transfer between the fluctuating velocity components of both phases across the interface. Many authors have proposed various approaches to close these terms. ${ }^{27,28,43,44}$ There is fairly good agreement on the fundamental form of the interaction term in the granular energy equation, $\pi_{\theta}$.

$$
\pi_{\theta}=\beta\left(\underline{\underline{u_{\mathrm{g}}^{\prime}} \cdot \underline{u_{\mathrm{s}}^{\prime}}}-\overline{\underline{u_{\mathrm{s}}^{\prime}} \cdot \underline{u_{\mathrm{s}}^{\prime}}}\right)=\beta\left(k_{\mathrm{sg}}-3 \theta\right)
$$

However, there is no consensus on the form of cross-correlation term $\left(k_{\mathrm{sg}}\right)$ in literature. Different cross-correlation terms have been proposed and tested in specific, mostly very dilute, flow regimes. ${ }^{31,43,45,46}$ In the present article, the particle fluctuations are expected to be unaffected by the details of gas fluctuations in the dilute plume region since the Stokes number is very high (Rangarajan D, Mychkovsky AG, Curtis JS, Ceccio SL. Effect of emulsion fluidization state on the fluctuations in gas and particle velocities inside the plume of a gas jet penetrating a fluidized bed. Powder Technol. 2011; submitted). Therefore, a form of cross-correlation proposed by Koch and Sangani ${ }^{46}$ that has been applied in dense-phase flows by Srivastava and Sundaresan ${ }^{26}$ is used here, to capture any interaction in the dense phase accurately.

$$
\beta k_{\mathrm{sg}}=\frac{81 \varepsilon_{\mathrm{s}} \mu_{\mathrm{g}}^{2}\left|\underline{u_{\mathrm{g}}}-\underline{u_{\mathrm{s}}}\right|^{2}}{g_{0} d_{\mathrm{p}}^{3} \rho_{\mathrm{s}} \sqrt{\pi \theta}}
$$

The turbulence interaction model description in the turbulent kinetic energy equation $\left(\pi_{k}\right)$, on the other hand, tends to be more fundamentally diverse. ${ }^{27,28,43}$ They differ in the mechanism for energy transfer which could be interphase drag or wake formation at the edge of particles, both of which could be significant in the high Reynolds number, dilute jet plume region. A general closure model for $\pi_{k}$, suitable for bubbling beds with jet injection, is currently not available and needs to be determined with the help of specific experimental data.

\section{Boundary conditions}

Finally, the boundary conditions for particle velocity and granular temperature at the wall are obtained from the commonly used equations of Johnson and Jackson, ${ }^{47}$ who derived a semiempirical partial slip condition arising from collisional momentum loss at the wall. The value for the specularity coefficient $(\varphi)$, an empirical constant that estimates the degree of roughness at the wall, is chosen as 0.002 following Bolio et al. ${ }^{28}$

$$
\begin{aligned}
& \underline{n} \cdot\left(\underline{\underline{\sigma_{\mathrm{s}}^{\mathrm{kc}}}}+\underline{\underline{\sigma_{\mathrm{s}}^{\mathrm{f}}}}\right) \\
& \quad \cdot \frac{\underline{u_{\mathrm{s}}}}{\mid \underline{u_{\mathrm{s}} \mid}}+\left(\underline{n} \cdot \underline{\underline{\sigma_{\mathrm{s}}^{\mathrm{f}}}} \cdot \underline{n}\right) \tan \delta_{\mathrm{w}}+\frac{\pi \sqrt{3}}{6 \varepsilon_{\mathrm{s}}^{\max }} \varphi \rho_{\mathrm{s}} \varepsilon_{\mathrm{s}} g_{0} \sqrt{\theta}\left|\underline{u_{\mathrm{s}}}\right|=0
\end{aligned}
$$

Table 2. System Parameters

\begin{tabular}{llll}
\hline Parameter & \multicolumn{1}{c}{ Description } & \multicolumn{1}{c}{ Experiment $^{23}$} & Present Sstudy \\
\hline$d_{\mathrm{p}}$ & Particle diameter & $838 \mu \mathrm{m}$ & Same \\
$\rho_{\mathrm{s}}$ & Particle density & $900 \mathrm{~kg} / \mathrm{m}^{3}$ & Same \\
$E$ & Particle-particle coefficient of restitution & - & 0.9 \\
$e_{\mathrm{w}}$ & - & 0.5 \\
$\varepsilon_{\mathrm{s}}{ }^{\max }$ & Particle-wall coefficient of restitution & - & 0.65 \\
$\delta_{\mathrm{w}}$ & Maximum packing fraction & - & $27 \mathrm{deg}$ \\
$H_{\mathrm{b}}$ & Angle of internal friction & - & $13 \mathrm{deg}$ \\
$T$ & Angle of wall friction & $38 \mathrm{~cm}$ & Same \\
$M W$ & Bed height at maximum packing & - & $29 \mathrm{~K}$ \\
$\mu_{\mathrm{g}}$ & Gas temperature & $29(\mathrm{air})$ & $\mathrm{Same}$ \\
$L$ & Gas molecular weight & - & $1.8 \mathrm{e}-5 \mathrm{~kg} /(\mathrm{ms})$ \\
$H$ & Gas viscosity & $0.457 \mathrm{~m}$ & $\mathrm{Same}$ \\
$W$ & Column width & $1 \mathrm{~m}$ & $4.35 \mathrm{~m}$ \\
$V_{\mathrm{j}}$ & Column height & $12.7 \mathrm{~mm}$ & Neglected \\
$D_{\mathrm{j}}$ & Column thickness & $92 \mathrm{~m} / \mathrm{s}$ & Same \\
$L_{\mathrm{p}}$ & Vertical jet inlet velocity & $9.2 \mathrm{~mm}$ & Same \\
$V_{f l}$ & Vertical jet diameter & $35 \mathrm{~cm}$ & Same \\
\hline
\end{tabular}




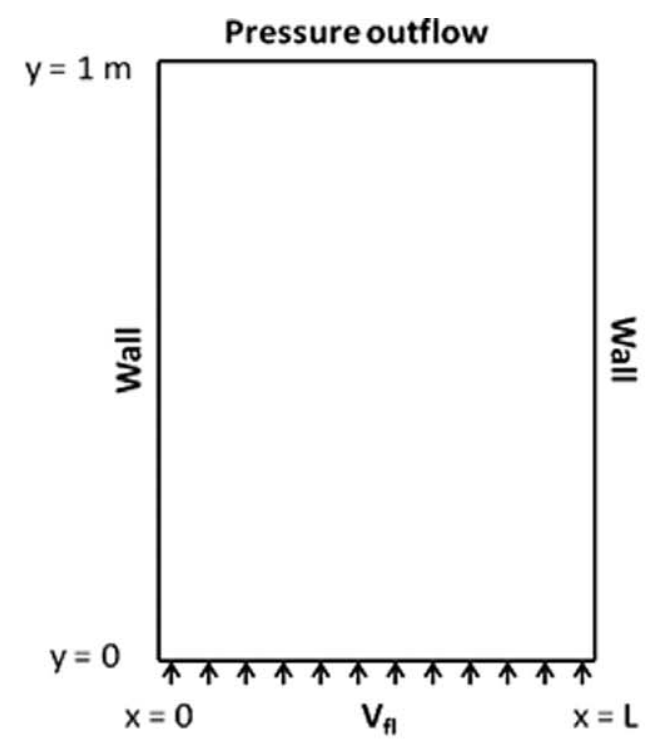

(a)

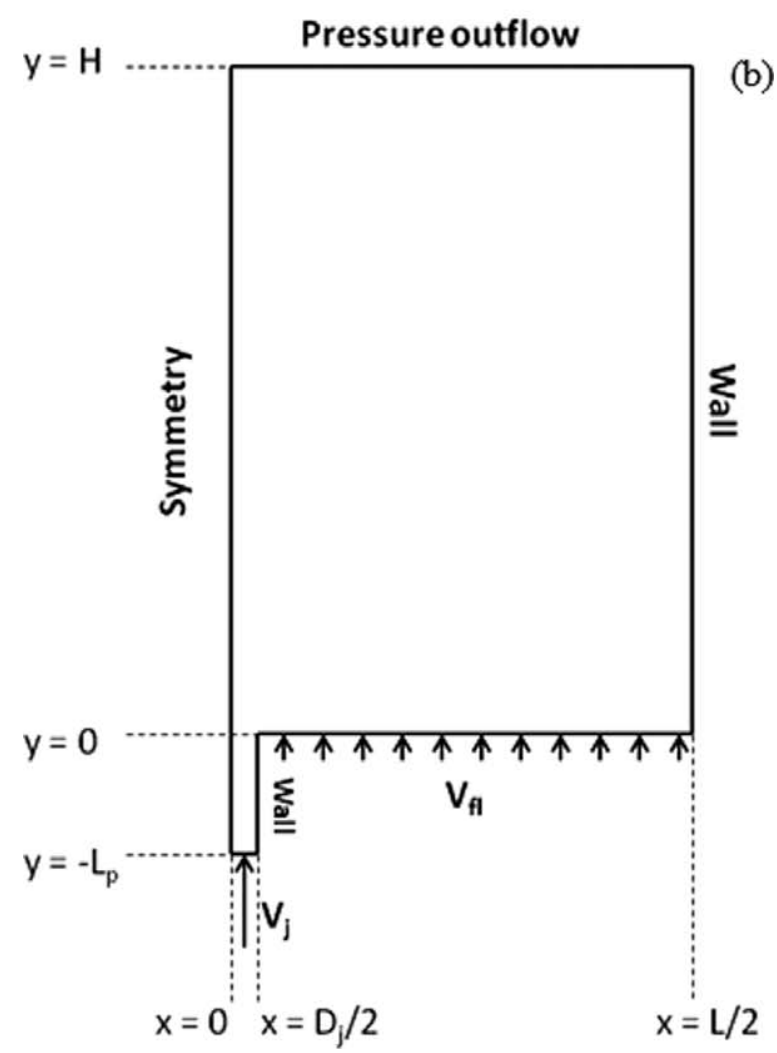

Figure 2. Simulation domain and boundary conditions used.

(a) Domain 1. (b). Domain 2. For the case $V_{f l}=0$, wall boundary conditions were imposed at the bottom distributor plate $\left(y=0, D_{\mathrm{j}} / 2<x<L / 2\right)$.

$$
\underline{n} \cdot\left(\kappa_{\mathrm{s}} \nabla \theta\right)=\frac{\pi \sqrt{3}}{6 \varepsilon_{\mathrm{s}}^{\max }} \varphi \rho_{\mathrm{s}} \varepsilon_{\mathrm{s}} g_{0} \sqrt{\theta}\left|\underline{u_{\mathrm{s}}}\right|^{2}-\frac{\pi \sqrt{3}}{4 \varepsilon_{\mathrm{s}}^{\max }}\left(1-e_{\mathrm{w}}^{2}\right) \rho_{\mathrm{s}} \varepsilon_{\mathrm{s}} g_{0} \theta^{\frac{3}{2}}
$$

Here, $\underline{n}$ is the unit normal to the wall, $\delta_{\mathrm{w}}$ is the angle of wall friction, $\varepsilon_{\mathrm{s}}^{\max }$ is the maximum packing fraction, and $e_{\mathrm{w}}$ is the coefficient of restitution between the particle and the wall.

Standard single-phase wall functions are imposed for the gas phase. ${ }^{48}$ The wall boundary conditions are not expected to play a major role in bubbling bed flows unlike pneumatic pipe flows which are significantly influenced by pipe walls.

\section{Model summary}

Appropriate closure models for the present gas-solid continuum framework have been carefully selected from currently available models. Most closure relations agree with the default models (Table 1) implemented in the US Department of Energy open source code, multiphase flows for interphase exchanges (MFIX). However, the description for three terms, namely, the multiplier in the frictional pressure expression, frictional viscosity model, and gas turbulence modulation term, still remain undetermined. The challenge lies in finding an appropriate way to close these terms before the overall continuum model may be validated in predicting the flow details inside the jet plume of a bubbling fluidized bed.

\section{Simulation Setup}

The model equations in the continuum framework were solved using MFIX. The details of the numerical technique can be found in Syamlal et al. ${ }^{39}$ The maximum residual at convergence was set to $1 \mathrm{e}-3$ for the continuity and momentum equations combined and 1e-4 for the granular energy, turbulent kinetic energy, and turbulent dissipation equations, respectively. The particle properties, gas properties, and boundary conditions for the simulations were input in agreement with the real experimental system wherever possible (Table 2). The experiments were conducted in a bed of highdensity polyethylene particles (Geldart B) with a high-speed vertical jet, and transverse velocity profiles were measured at different axial locations inside the jet plume. The variable in the experiments was the fluidization velocity, which was changed between 0 and 1.5 times minimum fluidization velocity. A detailed description of the experimental setup can found in Mychkovsky. ${ }^{49}$ The main difference between the experiment and simulation parameters was in the column height. Experiments with a vertical jet were made in a short column with a wire screen installed at the top which prevented loss of particles. In simulations, the corresponding prevention of loss of solids from the top of the column was

Table 3. Details of the Meshes Used*

\begin{tabular}{lll}
\hline & \multicolumn{2}{c}{ Mesh Arrangement } \\
\cline { 2 - 3 } Mesh Name & \multicolumn{1}{c}{ Along X-Direction from $x=0$} & \multicolumn{1}{c}{ Along Y-Direction from Bottom } \\
\hline Mesh 1 & $(50) 9.14 \mathrm{e}-3 \mathrm{~m}$ & $(50) 1 \mathrm{e}-2 \mathrm{~m},(10) 5 \mathrm{e}-2 \mathrm{~m}$ \\
Mesh 2 & $(15) 1.33 \mathrm{e}-3 \mathrm{~m},(25) 3.48 \mathrm{e}-3 \mathrm{~m},(10) 1.22 \mathrm{e}-2 \mathrm{~m}$ & $(15) 2.3 \mathrm{e}-2 \mathrm{~m},(40) 5 \mathrm{e}-3 \mathrm{~m},(60) 1.33 \mathrm{e}-2 \mathrm{~m},(75) 4 \mathrm{e}-2 \mathrm{~m}$ \\
Mesh 3 & $(30) 6.67 \mathrm{e}-4 \mathrm{~m},(50) 1.74 \mathrm{e}-3 \mathrm{~m},(20) 6.08 \mathrm{e}-3 \mathrm{~m}$ & $(15) 2.3 \mathrm{e}-2 \mathrm{~m},(80) 2.5 \mathrm{e}-3,(120) 6.67 \mathrm{e}-3 \mathrm{~m},(150) 2 \mathrm{e}-2 \mathrm{~m}$ \\
\hline
\end{tabular}

*Arrangement shows "(number of cells) size of each cell". 
(b)

(a)

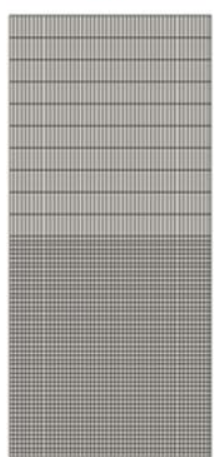

Figure 3. Illustration of mesh arrangement: (a) Mesh 1. (b) Mesh 2.

[Color figure can be viewed in the online issue, which is available at wileyonlinelibrary.com.]

achieved by specifying a very tall domain which allowed the solids to fall back down. Though the experiments were conducted in the presence of acrylic bounding walls (pseudo-2D arrangement), the development of self-similar velocity profiles for both phases inside the jet plume has been consistent with the analytical Gaussian profile for two-dimensional jets. $^{23,50,51}$ Therefore, the simulations conducted in this article were two-dimensional and the governing equations were not solved along the thickness direction.
Two different simulation domains and three different mesh arrangements have been used for simulations conducted in this article. The simulation domains and boundary conditions are shown in Figure 2 and the mesh arrangements are described in Table 3 and Figure 3. At the pipe inlet $\left(y=-L_{p}, x=0\right.$ to $\left.D_{\mathrm{j}} / 2\right)$ in Figure $2 \mathrm{~b}$, turbulence values of $k_{j}=21 \mathrm{~m}^{2} / \mathrm{s}^{2}$ and $\varepsilon_{j}=2.5 \mathrm{e} 4 \mathrm{~m}^{2} / \mathrm{s}^{3}$ were specified following standard computations fluid dynamics (CFD) guidelines corresponding to an inflow velocity of $V_{j}=92 \mathrm{~m} / \mathrm{s}$. For simulations with nonzero fluidization rates, a wall condition was imposed immediately next to the exit of the inlet pipe for a short distance of approximately $0.5 D_{\mathrm{j}}\left(y=0, x=D_{\mathrm{j}} / 2\right.$ to $\left.D_{\mathrm{j}}\right)$ before fluidization inflow conditions were specified. This ensured that there was no conflict in the ghost cell implementation of boundary conditions and also allowed for the inflow velocity and turbulence values to decay gradually. The sensitivity of this distance on the results was found to be negligible. All simulations were started from a uniform loosely packed bed, $\varepsilon_{\mathrm{s}}=0.5$, at stagnant conditions to speed up initial convergence.

\section{Results and Discussion}

The results are divided into four studies that compare simulation results with experimental data (Table 4). The first three studies find ways of describing the unclosed terms in the present continuum framework by benchmarking against available experimental data: Study 1 investigates the simple fluidization curve with the aim of independently determining the multiplier, Fr; Study 2 investigates the dense emulsion behavior in the presence of a jet to identify an appropriate frictional viscosity description; Study 3 investigates the gas turbulence profile inside the jet plume of a spouted bed to determine the most suitable turbulence modulation expression. Finally, the last study validates the predictive capabilities of the final overall continuum model against detailed mean and fluctuating velocity measurements of gas and particles inside the dilute jet plume region of a bubbling fluidized bed. The experimental data used for benchmarking and final validation are obtained from the works of Mychkovsky, ${ }^{49}$ Mychkovsky and Ceccio, ${ }^{22}$ and Rangarajan et al. (Rangarajan D, Mychkovsky AG, Curtis JS, Ceccio SL. Effect of emulsion fluidization state on the fluctuations in gas and particle velocities inside the plume of a gas jet penetrating a fluidized bed. Powder Technol. 2011; submitted). Mesh insensitivity was ensured before making quantitative comparisons in Study 1 and Study 3. While the same fine mesh used in Study 3 was used in Study 4, the high fluidization case of $V_{f l} / V_{m f}=1.3$ was simulated with double the grid

Table 4. Closure for the Undetermined Terms in Each Study

\begin{tabular}{|c|c|c|c|c|c|}
\hline \multirow[b]{2}{*}{ Study } & \multirow[b]{2}{*}{ Flow Simulated } & \multirow[b]{2}{*}{ Property Investigated } & \multicolumn{3}{|c|}{ Uncertainties in Closure } \\
\hline & & & $F r$ & $\mu_{\mathrm{s}}^{\mathrm{f}}$ & $\pi_{k}$ \\
\hline 1 & Fluidization & Pressure drop across the bed & $\begin{array}{l}\text { Varied }(0.01 \\
0.05,0.5 \mathrm{~Pa})\end{array}$ & Does not play a role & Does not play a role \\
\hline 2 & $\begin{array}{l}\text { Jet injection into a } \\
\text { fluidized bed }\end{array}$ & Dynamic emulsion behavior & $0.05 \mathrm{~Pa}$ & $\begin{array}{l}\text { Varied (Savage, } \\
\text { Srivastava and } \\
\text { Sundaresan, }{ }^{26} \\
\text { Schaeffer }^{41} \text { ) }\end{array}$ & Does not play a role \\
\hline 3 & Spouted bed & $\begin{array}{l}\text { Gas turbulence profile inside } \\
\text { the jet plume }\end{array}$ & $0.05 \mathrm{~Pa}$ & Savage $^{42}$ & $\begin{array}{l}\text { Varied } \\
\qquad\left(0, \pi_{k}^{\text {drag }}, \pi_{k}^{\text {drag }}+\pi_{k}^{\text {wake }}\right)\end{array}$ \\
\hline 4 & $\begin{array}{l}\text { Jet injection into a } \\
\text { fluidized bed }\end{array}$ & $\begin{array}{l}\text { Mean and fluctuating velocity } \\
\text { profiles inside the jet plume }\end{array}$ & $0.05 \mathrm{~Pa}$ & Savage $^{42}$ & $\pi_{k}^{\text {drag }}+\pi_{k}^{\text {wake }}$ \\
\hline
\end{tabular}




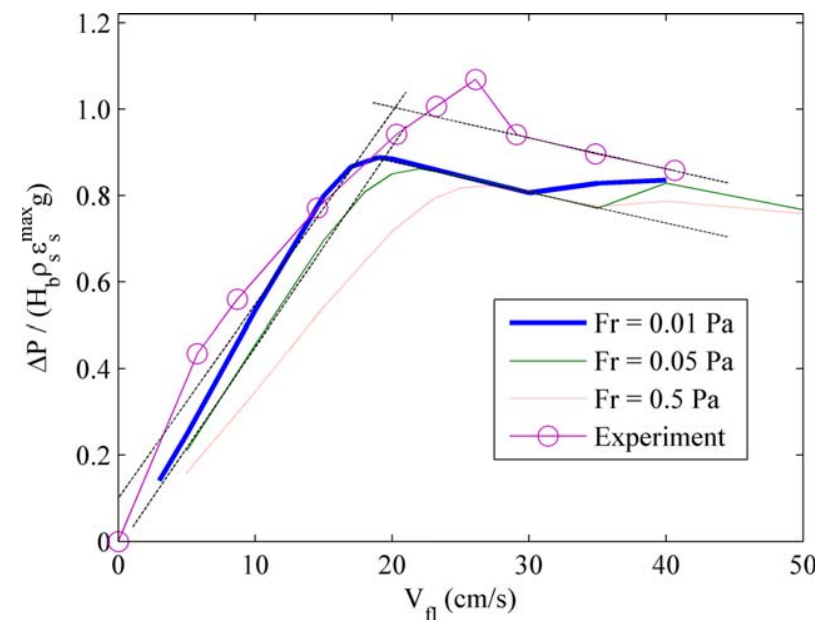

Figure 4. Sensitivity of the fluidization curve to frictional pressure multiplier and final match with experiment.

[Color figure can be viewed in the online issue, which is available at wileyonlinelibrary.com.]

density in the emulsion region to check the influence of mesh on the time-averaged results. Negligible influence in the time-averaged mean and about $10 \%$ deviation in the time-averaged velocity fluctuations were observed.

\section{Study 1: Determining multiplier in frictional pressure expression}

Simulation domain 1 and Mesh 1 were used for this study as described in Figure 2a and Table 3, respectively. In this study, there is no vertical jet and hence no descriptions for the gas phase turbulence and gas turbulence interaction were necessary. The default form for frictional viscosity come from Srivastava and Sundaresan. ${ }^{26}$ Fluidization velocities ranging from $V_{f l}=5$ to $50 \mathrm{~cm} / \mathrm{s}$ were simulated for different values of the multiplier $F r$. Each simulation was run for $3 \mathrm{~s}$ of real time, after which the gas pressure drop across the bed $(\Delta P)$ reached a steady value. The continuum model pressure drop predictions were normalized and compared against experiment.

The sensitivity of the simulation fluidization curve to the multiplier $\mathrm{Fr}$ is shown in Figure 4. Increasing $\mathrm{Fr}$ decreases the slope of the packed bed pressure drop accompanied by an increase in the minimum fluidization velocity prediction. This is because with increase in $F r$, higher frictional forces are estimated between particles, resulting in a decrease in the packing fraction thereby decreasing the gas-solid drag. After attempting a range of values for $F r$, it was found that $F r=0.05 \mathrm{~Pa}$ predicted closest agreement with experiment in terms of both the slope of the packed bed region, and the point where the packed bed and fluidization lines meet in the fluidization curve (Figure 4). However, it can be seen that the simulation is unable to capture the bump in the experimental curve close to minimum fluidization, which is expected since the model neglects electrostatic and cohesive effects between particles. To be consistent with the experiment, the minimum fluidization value in the present article is chosen to be $V_{m f}=29 \mathrm{~cm} / \mathrm{s}$, which falls just after the bump. Finally, it was ensured that the description for frictional viscosity did not affect pressure drop predictions by conducting the fluidization simulations using different viscosity models, including artificially imposing zero frictional viscosity (Figure 5). This study also shows how fluidization curves

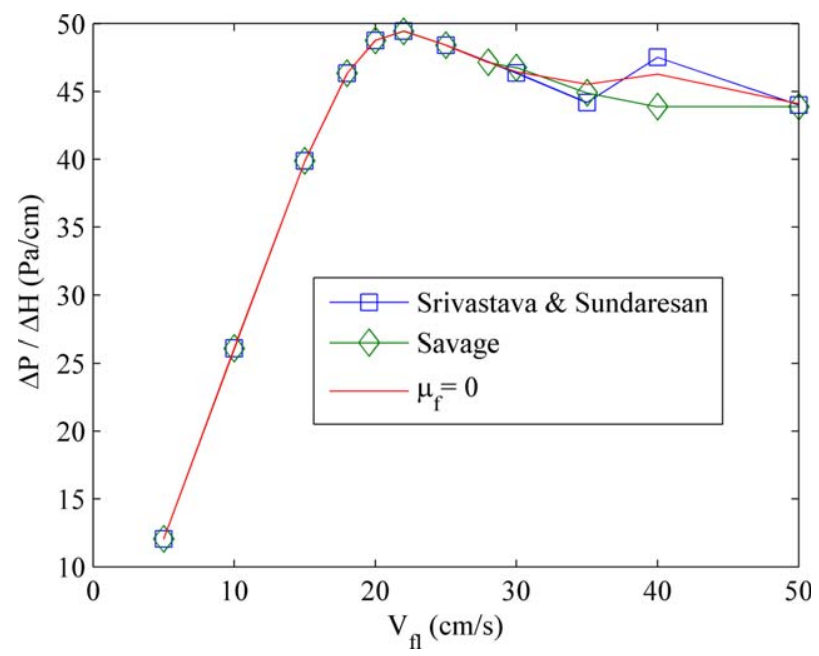

Figure 5. Effect of frictional viscsoity expression in predicting the fluidization curve: $F r=0.05 \mathrm{~Pa}$.

[Color figure can be viewed in the online issue, which is available at wileyonlinelibrary.com.]

can be a robust tool to validate the empirical constants in the frictional pressure expression without the influence of other uncertainties in the continuum framework, such as the form of frictional viscosity or turbulence interaction.

\section{Study 2: Determining frictional viscosity model}

The aim of this study is to qualitatively compare the macroscopic flow pattern predicted by the continuum model in the presence of a jet against the experiment and to ensure that the key dense flow dynamics are captured by the frictional model. The simulation domain is shown in Figure $2 \mathrm{~b}$. A nonuniform mesh (Mesh 2) with more grids close to the jet orifice, where the gradients are expected to be high, was chosen for the study (Table 3). The turbulence interaction term is not expected to influence the qualitative dense phase behavior and was assumed to be zero in the continuum model adopted in this section. From the results of study 1 ,

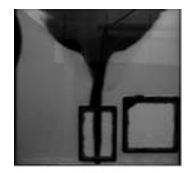

(a)

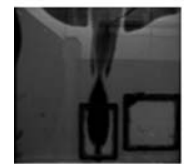

(e)

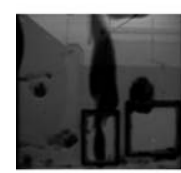

(i)

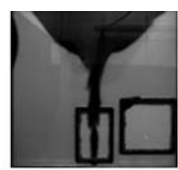

(b)

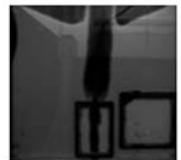

(f)

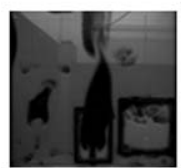

(j)

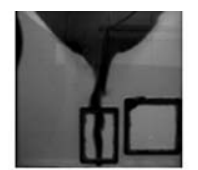

(c)

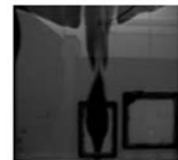

(g)

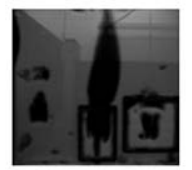

(k)

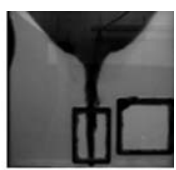

(d)

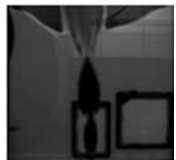

(h)

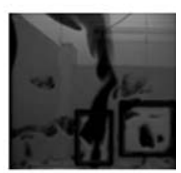

(1)
Figure 6. Photographs of the experiment at increasing intervals of $1 \mathrm{~s}$.

The black portion represents voids and the white portion represents bed particles. (a-d) $V_{f l}=0$, (e-h) $V_{f l}=V_{m f}$, and (i-l) $V_{f l}=1.5 V_{m f}$. 


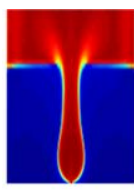

(a)

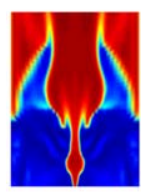

(e)

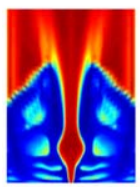

(i)

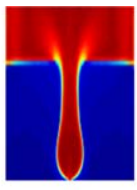

(b)

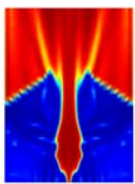

(f)

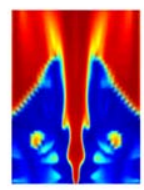

(j)

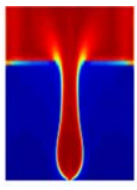

(c)

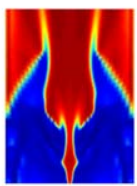

(g)

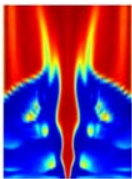

(k)

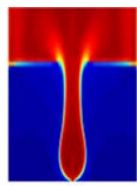

(d)

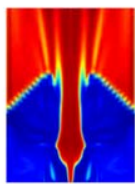

(h)

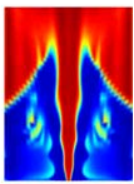

(1)

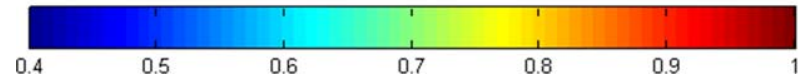

Figure 7. Gas volume fraction prediction of Savage frictional viscosity.

(a-d) $V_{f l}=0$ at $t=5,5.5,6$, and $6.5 \mathrm{~s}$. (e-h) $V_{f l}=V_{m f}$ at $t=5,6,7$, and $8 \mathrm{~s}$. (i-l) $V_{f l}=1.5 V_{m f}$ at $t=5,6,7$, and $8 \mathrm{~s}$. [Color figure can be viewed in the online issue, which is available at wileyonlinelibrary.com.]

the multiplier $\mathrm{Fr}$ was chosen to be $0.05 \mathrm{~Pa}$. Fluidization velocities of $V_{f l}=0, V_{m f}$, and $1.5 V_{m f}$ were simulated for a period of $15 \mathrm{~s}$ of real time, and the macroscopic concentration predictions were compared with digital videos taken from experiment. Frictional viscosity description in the continuum model was changed between that of Savage as implemented in MFIX (Eq. 30) and Srivastava and Sundaresan (Eq. 31).

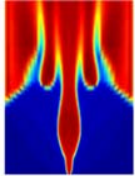

(a)

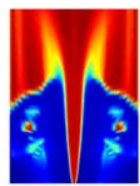

(e)

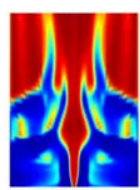

(i)

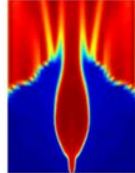

(b)

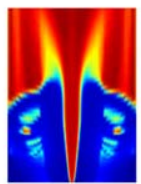

(f)

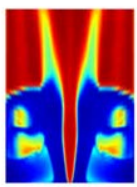

(j)

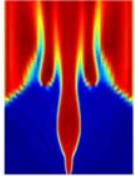

(c)

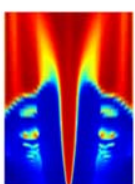

(g)

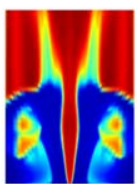

(k)

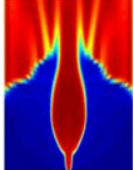

(d)

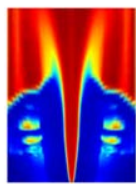

(h)

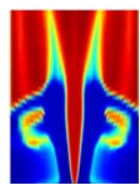

(1)

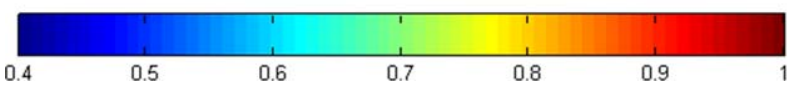

Figure 8. Gas volume fraction prediction of Srivastava and Sundaresan frictional viscosity.

(a-d) $V_{f l}=0$ at $t=5,5.5,6$, and $6.5 \mathrm{~s}$. (e-h) $V_{f l}=V_{m f}$ at $t=5,6,7$, and $8 \mathrm{~s}$. (i-l) $V_{f l}=1.5 V_{m f}$ at $t=5,6,7$, and $8 \mathrm{~s}$. [Color figure can be viewed in the online issue, which is available at wileyonlinelibrary.com.]

$$
\begin{gathered}
\mu_{\mathrm{s}}^{\mathrm{f}}=\frac{p_{\mathrm{s}}^{\mathrm{f}} \sin \delta}{\sqrt{2}} \sqrt{\frac{\mu_{\mathrm{s}}^{\mathrm{kc}}}{J_{\mathrm{s}} \varepsilon_{\mathrm{s}} \rho_{\mathrm{s}}}} \\
\mu_{\mathrm{s}}^{\mathrm{f}}=\frac{p_{\mathrm{s}}^{\mathrm{f}} \sin \delta}{\sqrt{2}} \frac{1}{\sqrt{\underline{\underline{S_{\mathrm{s}}}}: \underline{\underline{S_{\mathrm{s}}}}+\theta / d_{\mathrm{p}}^{2}}}
\end{gathered}
$$

Figures 6 show the dynamic flow behavior for the experiment and each of the frictional viscosity models with increasing fluidization velocity, at intervals of approximately $1 \mathrm{~s}$ real time. While the absolute time does not matter, a generous period of $5 \mathrm{~s}$ was given for the simulations from the start to avoid any effects of initial conditions. It is seen that in the experiment, the spouted bed case, $V_{f}=0$, shows a generally steady behavior with a stable plume boundary formation. Upon increasing the fluidization velocity to $V_{m f}$, the plume boundary shows instability as it interacts with the fluidized emulsion region. Small, sparse bubbles can be seen in the emulsion region. At a still higher fluidization velocity

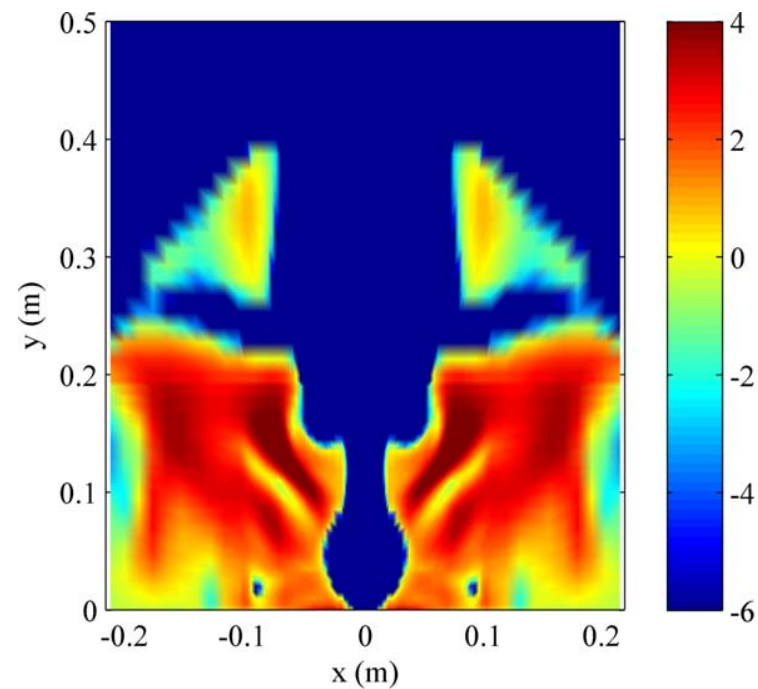

(a)

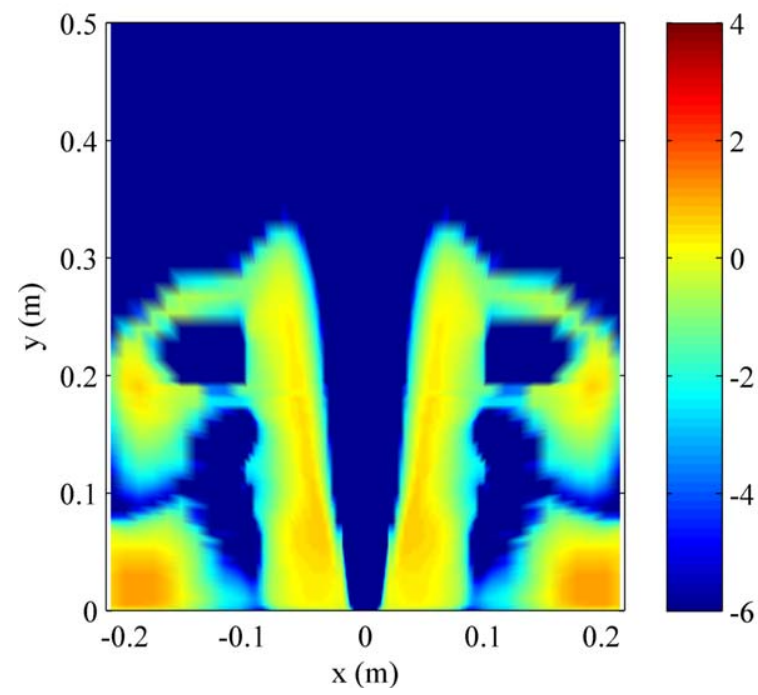

Figure 9. Frictional viscosity values on a log scale for $V_{f l}=V_{m f}$ at $t=15 \mathrm{~s}$.

(a) Predictions by savage and (b) predictions by Srivastava and Sundaresan. [Color figure can be viewed in the online issue, which is available at wileyonlinelibrary.com.] 


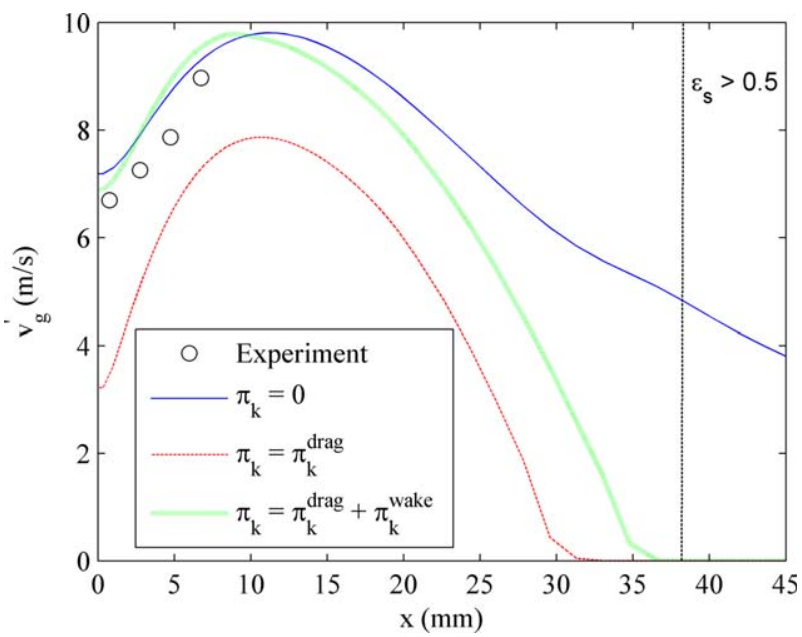

Figure 10. Influence of gas turbulence modultion term on the gas fluctuating velocity at $y=0.1 \mathrm{~m}$ for $V_{f l}=0$.

[Color figure can be viewed in the online issue, which is available at wileyonlinelibrary.com.] of $V_{f l}=1.5 V_{m f}$, the plume boundary displays high instability as large bubbles move toward and interact with the jet plume from the emulsion region (Figure 6). Similar qualitative behavior is captured by the Savage frictional viscosity expression, Eq. 30 (Figure 7). Conversely, corresponding predictions from Srivastava and Sundaresan form of frictional viscosity (Eq. 31), show unstable behavior at $V_{f}=0$, a stable plume boundary at a fluidization rate of $V_{m f}$ and large bubbles in the emulsion that tend to move in distinct vertical channels away from the jet axis at fluidization rates of $V_{f l}=V_{m f}$ and $1.5 V_{m f}$ (Figure 8). The poor performance of the Srivastava and Sundaresan model (Eq. 31) in predicting the macroscopic flow pattern is estimated to be because this model tends to predict low frictional viscosity that makes the solid phase too liquid-like (Figure 9).

Finally, the fluidization case of $V_{f l}=V_{m f}$ was simulated with Schaeffer viscosity model (Eq. 32) and was found to behave the same way as Srivastava and Sundaresan (Eq. 31), form suggesting that the mean strain rate dominates in predicting frictional viscosity in Eq. 31.
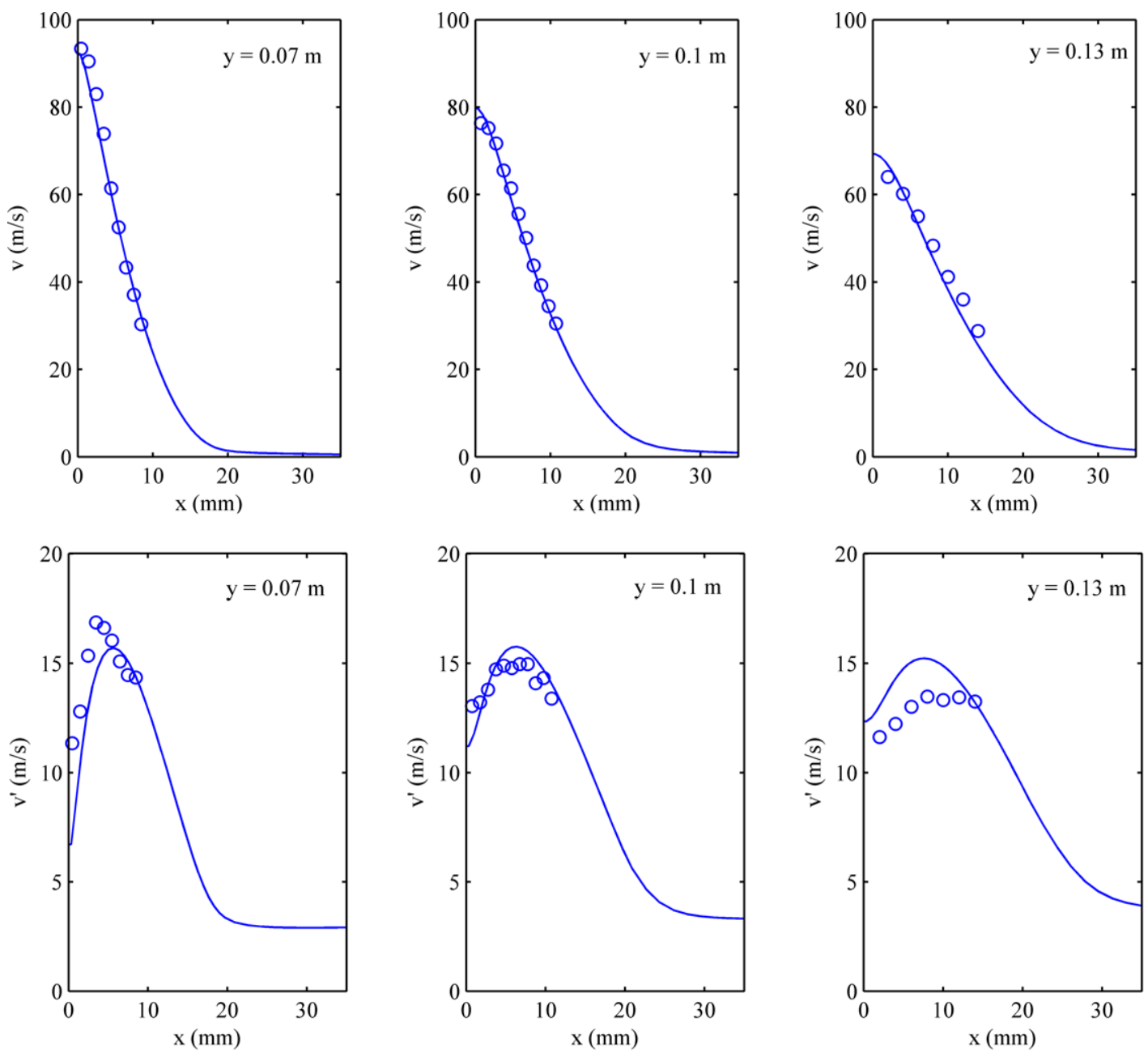

(b)

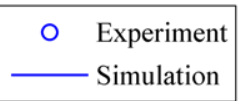

Figure 11. Streamwise velocity profiles for single phase jet.

(a) Mean velocity and (b) fluctuating velocity. [Color figure can be viewed in the online issue, which is available at wileyonlinelibrary.com.] 

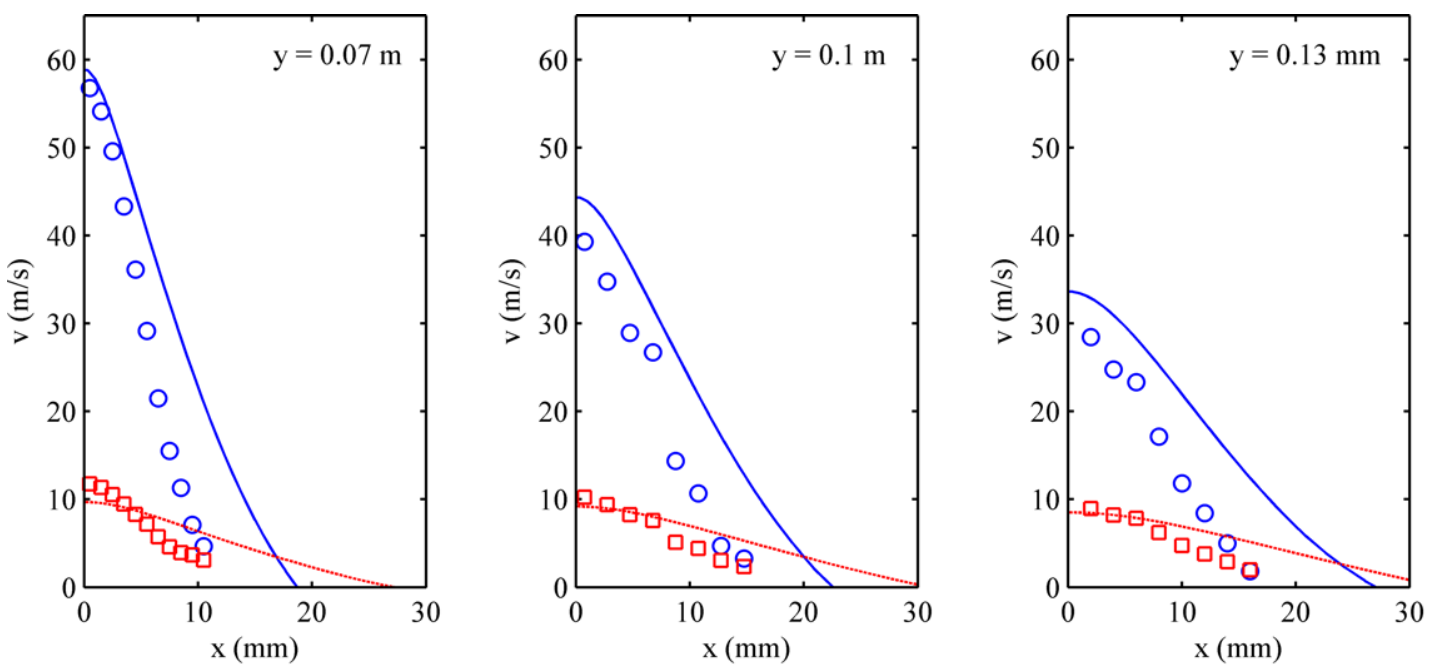

(a)
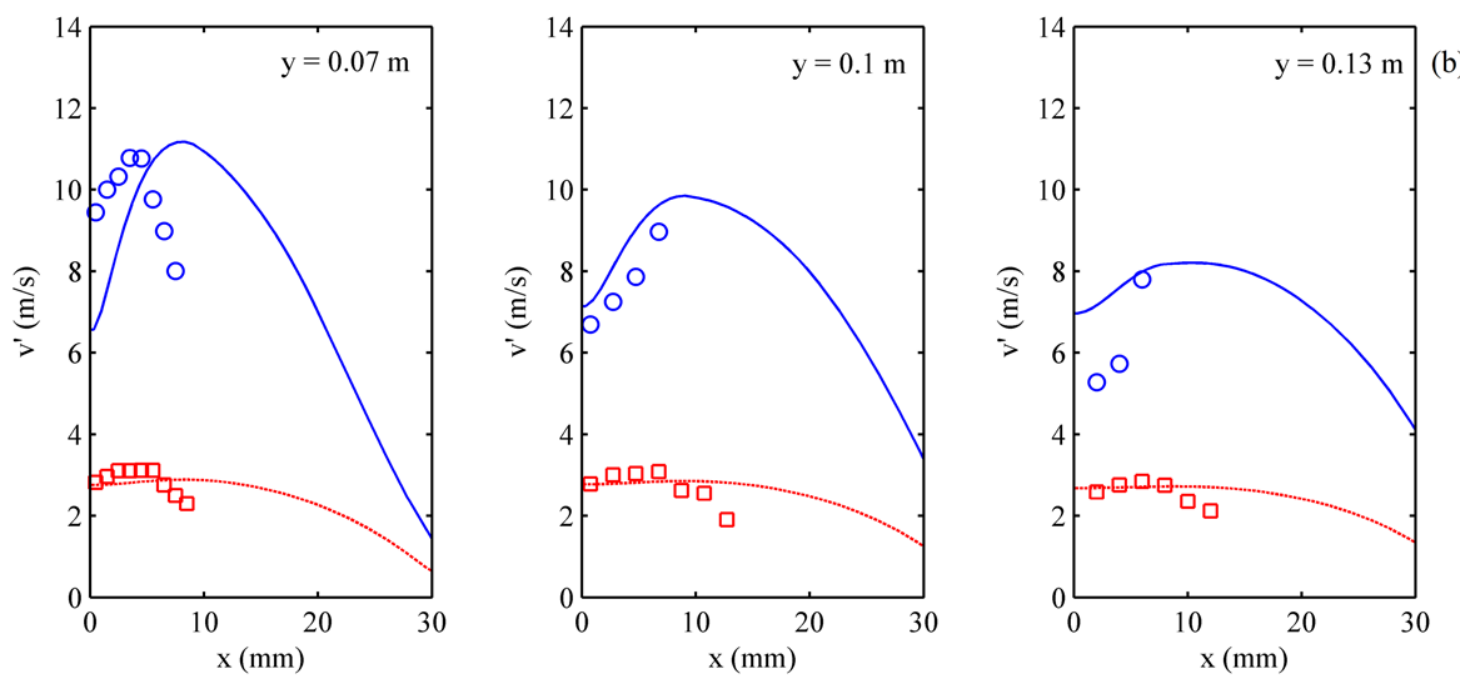

(b)

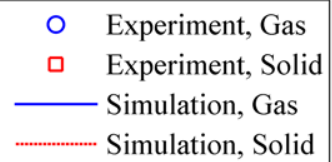

Figure 12. Streamwise velocity profiles for $V_{f l}=0$.

(a) Mean velocity and (b) fluctuating velocity. [Color figure can be viewed in the online issue, which is available at wileyonlinelibrary.com.]

$$
\mu_{\mathrm{s}}^{\mathrm{f}}=\frac{p_{\mathrm{s}}^{\mathrm{f}} \sin \delta}{\sqrt{2}} \frac{1}{\sqrt{\underline{\underline{S_{\mathrm{s}}}}}: \underline{\underline{S_{\mathrm{s}}}}}
$$

Due to better match with macroscopic dynamics of the experiment, the Savage frictional viscosity expression (Eq. 30 ) is used in the present overall continuum model.

\section{Study 3: Determining turbulence modulation term}

Since the continuum model predicts turbulent kinetic energy and granular kinetic energy, whereas the experimental measurements provide fluctuating velocities only in the streamwise direction, anisotropies in the gas phase and particle phase have to be assumed before fluctuating velocity comparisons can be made. These assumptions regarding the anisotropy in the two phases may be avoided if the Reynolds stresses for the gas and solids phases are solved, as done in the works of Dan et al. ${ }^{52,53}$ However, this approach generates an additional six equations per phase and would add significant computational burden on the simulations. In the present article, the anisotropy in the gas phase turbulence is assumed to be the same as that of a singlephase planar turbulent jet. ${ }^{54}$ Conversely, the granular temperature is assumed to be isotropic based on the work of Jones ${ }^{55}$ who found that dilute flows of relatively large particles can be characterized by isotropic particle fluctuations. These assumptions simplify to

$$
\begin{gathered}
v_{\mathrm{g}}^{\prime}=\sqrt{\frac{k}{1.088}} \\
v_{\mathrm{s}}^{\prime}=\sqrt{\theta}
\end{gathered}
$$

A spouted bed simulation $\left(V_{f}=0\right)$ was conducted and the gas fluctuating velocity profile at a height $y=0.1 \mathrm{~m}$ $\left(10.87 D_{\mathrm{j}}\right)$ was matched with corresponding experimental data inside the jet plume. The frictional pressure multiplier and the closure for frictional viscosity were obtained from the 

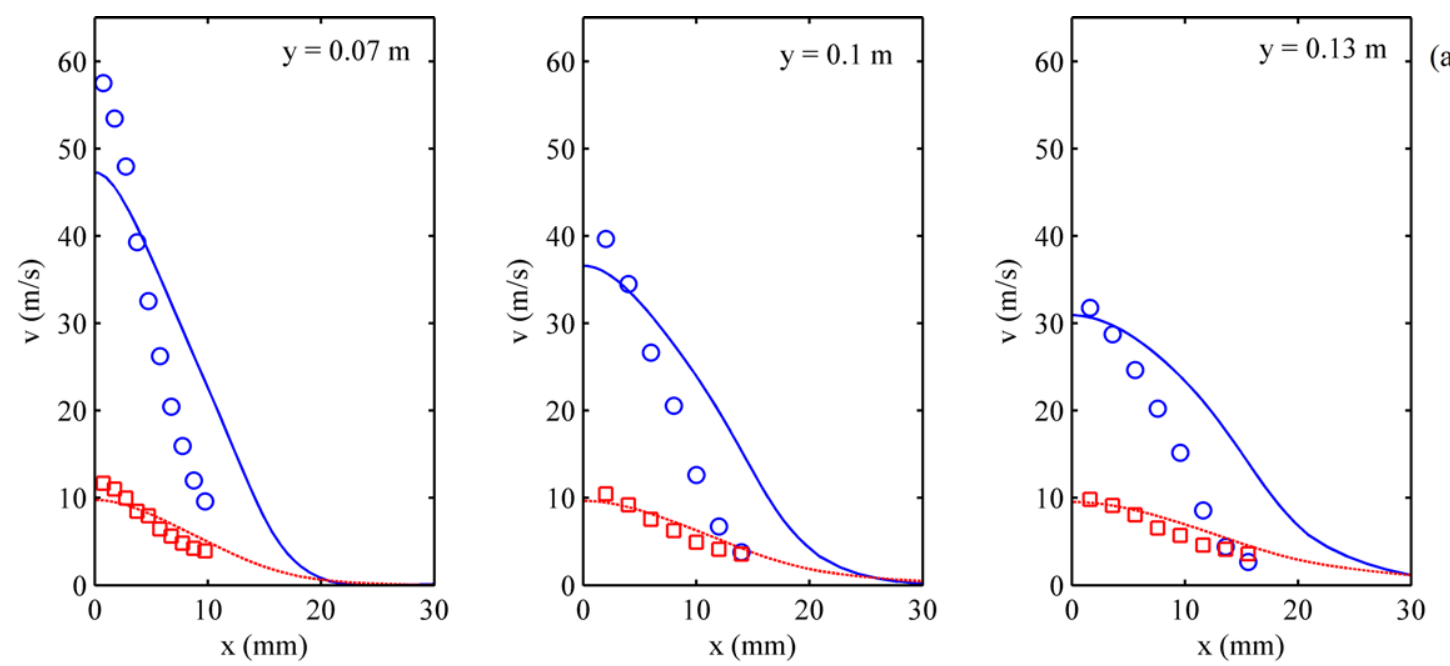

(a)
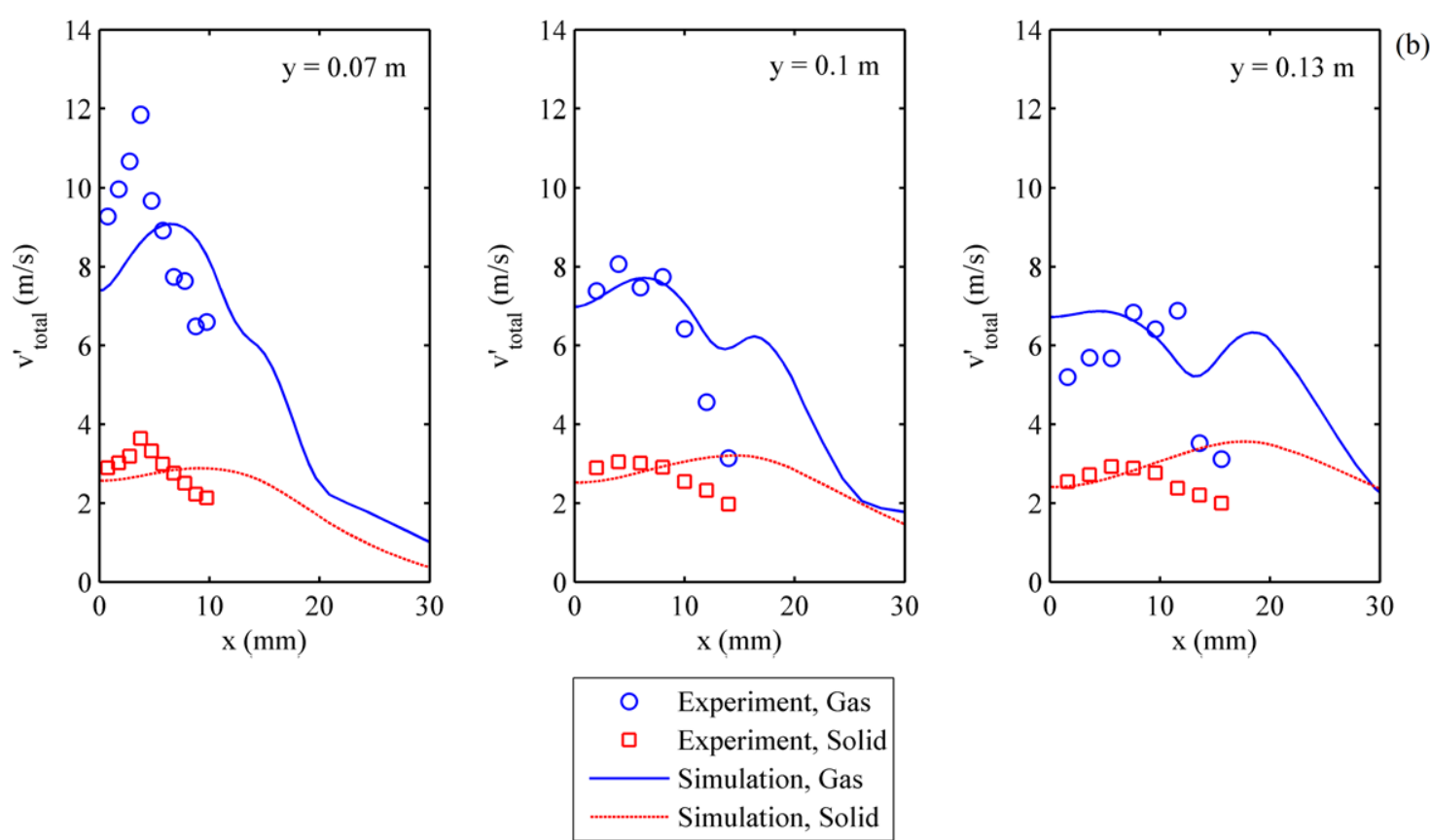

Figure 13. Streamwise velocity profiles for $V_{f l}=0.7 V_{m f}$.

(a) Mean velocity and (b) fluctuating velocity. [Color figure can be viewed in the online issue, which is available at wileyonlinelibrary.com.]

findings of Study 1 and Study 2, respectively. Mesh 3 (Table 3 ), which is a mesh arrangement similar to Study 2, but with double the mesh density was used. The simulation required 2 $\mathrm{s}$ of real time to predict a steady profile. To determine the significant mechanisms for the enhancement or dampening of gas turbulence due to particles, three forms of gas turbulence modulation term were considered.

$$
\begin{gathered}
\pi_{k}=0 \\
\pi_{k}=\pi_{k}^{\mathrm{drag}} \\
\pi_{k}=\pi_{k}^{\mathrm{drag}}+\pi_{k}^{\text {wake }}
\end{gathered}
$$

The first form (Eq. 35) assumes that there is no influence of particle fluctuations on gas turbulence, the second (Eq. 36) assumes that any enhancement or dampening of gas turbulence is only through instantaneous fluctuations in drag, whereas the third form (Eq. 37) includes the turbulence enhancement due to the formation of particle wakes in addition to drag. A widely accepted general expression, ${ }^{5}$ with cross-correlation function consistent with the interaction term in the granular energy equation, is specified for the drag contribution (Eq. 38). The wake contribution description, on the other hand, tends to be mostly ad-hoc in literature and a slightly modified form of Lun, ${ }^{56}$ which results in turbulence enhancement at high particle Reynolds numbers $\left(\operatorname{Re}_{\mathrm{p}}>1000\right)$ is used in this study (Eq. 39).

$$
\begin{gathered}
\pi_{k}^{\mathrm{drag}}=\beta\left(k_{\mathrm{sg}}-\underline{\underline{u_{\mathrm{g}}^{\prime}} \cdot \underline{u_{\mathrm{g}}^{\prime}}}\right)=\frac{81 \varepsilon_{\mathrm{s}} \mu_{\mathrm{g}}^{2}\left|\underline{u_{\mathrm{g}}}-\underline{u_{\mathrm{s}}}\right|^{2}}{g_{0} d_{\mathrm{p}}^{3} \rho_{\mathrm{s}} \sqrt{\pi \theta}}-2 \beta k \\
\pi_{k}^{\mathrm{wake}}=12 \frac{c_{\mathrm{w}} \mu_{\mathrm{t}} k}{d_{\mathrm{p}}^{2}} ; \mu_{\mathrm{t}}=0.029 \operatorname{Re}_{\mathrm{p}} \mu_{\mathrm{g}} ; \operatorname{Re}_{\mathrm{p}}=\frac{\rho_{\mathrm{g}} d_{\mathrm{p}}\left|\underline{u_{\mathrm{g}}}-\underline{u_{\mathrm{s}}}\right|^{2}}{\mu \mathrm{g}} \\
C_{\mathrm{w}}= \begin{cases}0, & \operatorname{Re}_{\mathrm{p}}<1000 \\
2, & \operatorname{Re}_{\mathrm{p}} \geq 1000\end{cases}
\end{gathered}
$$



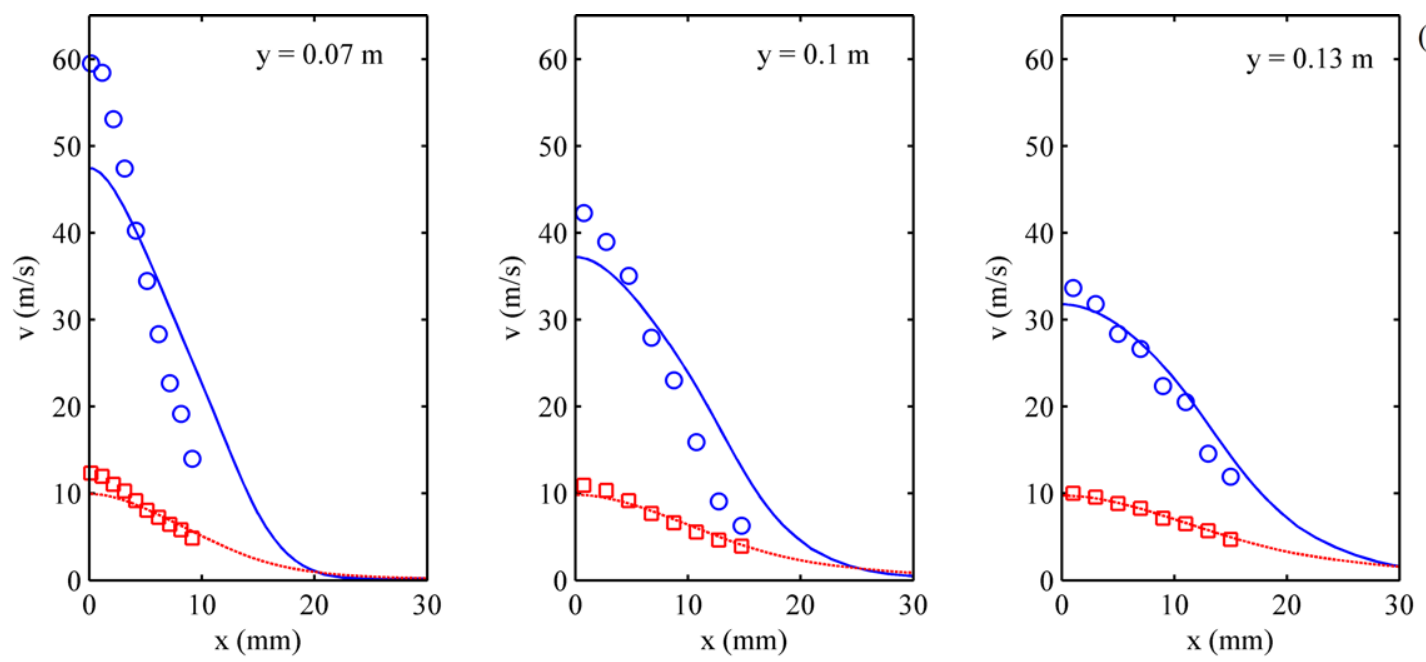

(a)
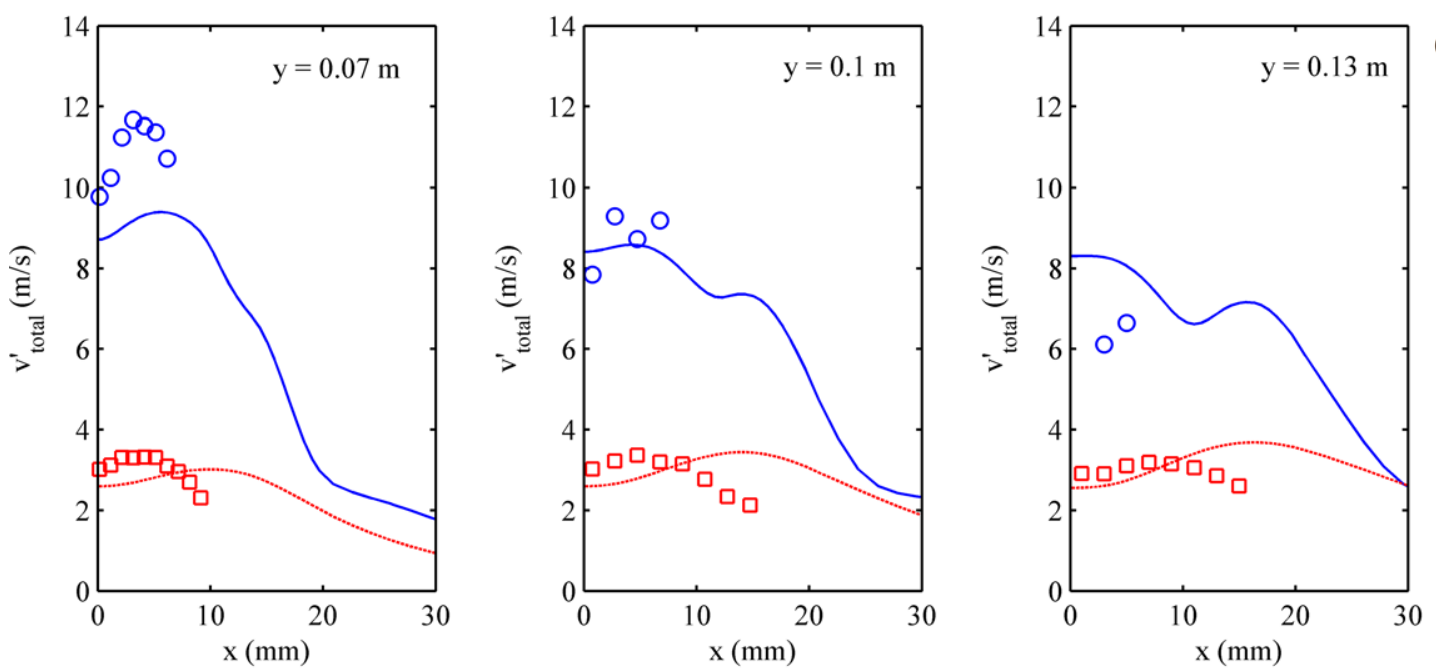

(b)

Figure 14. Streamwise velocity profiles for $V_{f l}=V_{m f}$.

(a) Mean velocity and (b) fluctuating velocity. [Color figure can be viewed in the online issue, which is available at wileyonlinelibrary.com.]

From Figure 10, it is seen that when the effect of particles on gas turbulence is ignored, abnormally high values of turbulence are predicted in the dense regions. Including the effect of instantaneous particle drag on turbulence is able to avoid this unphysical behavior but under-predicts the centerline gas fluctuations suggesting that there is turbulence enhancement due to wake formation as one would expect for the relatively large 838 micron particles. ${ }^{57}$ Finally, the form of interaction term that includes both the effect of instantaneous particle drag and the enhancement due to particle wakes is able to avoid the unrealistically high turbulence in the dense regions and captures the gas fluctuations near the centerline accurately. Because of the realistic turbulence prediction and good match with experiment, the gas turbulence interaction model expressed in Eqs. 37 is used in the final continuum framework.

\section{Study 4: Validation of the final continuum model}

Before comparing detailed velocity profiles predicted by the two-phase model against experimental data, a single phase validation was carried out using Mesh 3. Figure 11 shows excellent match between simulation and experiment in both mean and fluctuating velocity at heights $y=0.07,0.1$, and $0.13 \mathrm{~m}$. This match validates that the inlet conditions in the experiment are accurately captured in simulations and also confirms that there is no significant shortcoming in neglecting the bounding walls with regard to the singlephase case. $^{58}$

Finally, two-phase simulations with the same fine mesh used in Study 3 were conducted for $V_{f l}=0,0.7 V_{m f}, V_{m f}$, $1.3 V_{m f}$, and $1.5 V_{m f}$. The closure for the frictional pressure multiplier, frictional viscosity expression, and turbulence modulation term come from Study 1, Study 2, and Study 3, respectively (Table 4). As seen in the earlier studies, while the spouted bed case, $V_{f l}=0$ predicts steady profiles after $2 \mathrm{~s}$ of real time, the higher fluidization rates do not reach a steady state because of the dynamic emulsion phase. Therefore, these simulations were run for a long time, after which the time average of four quantities - the mean velocity, 

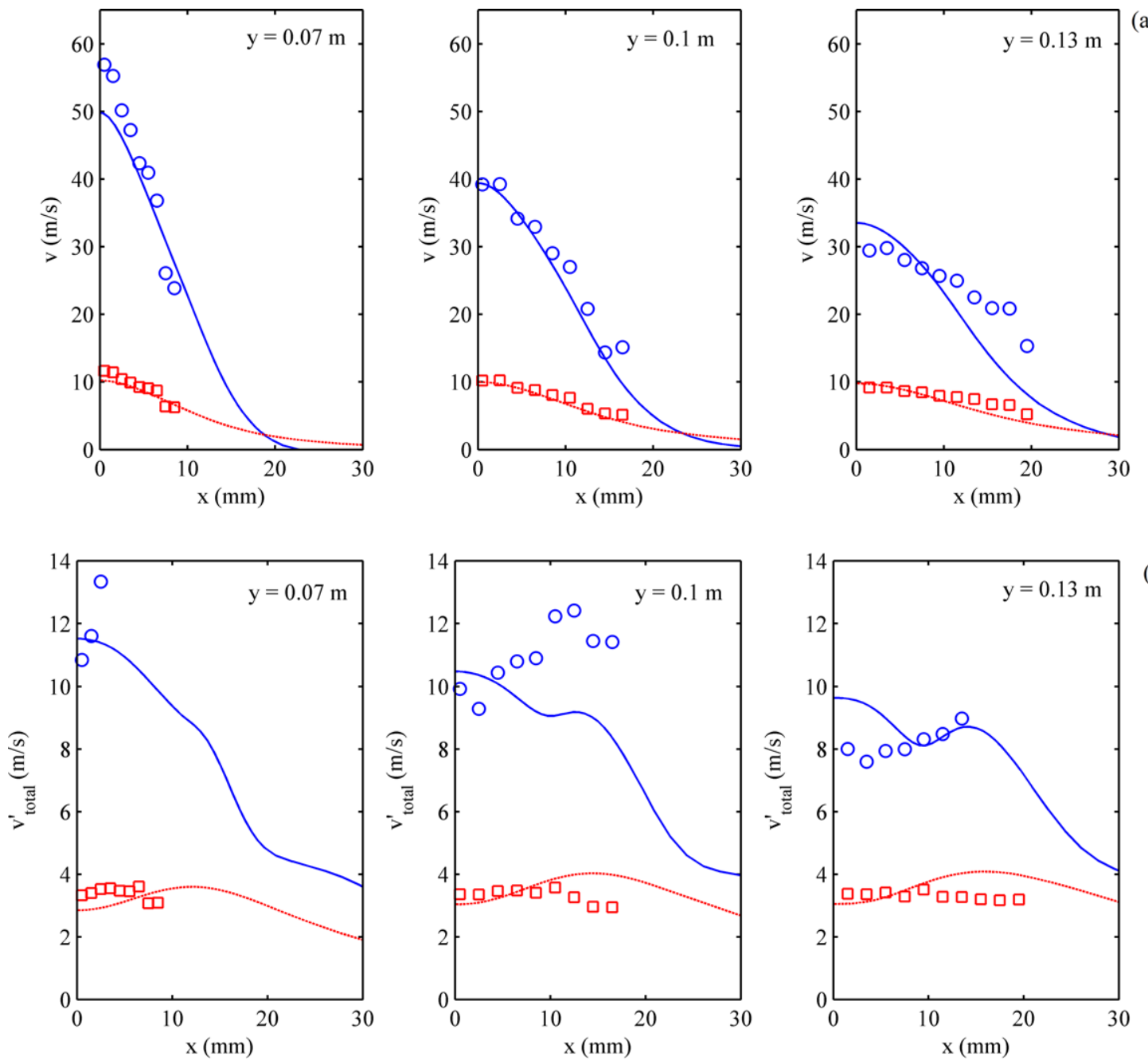

(b)

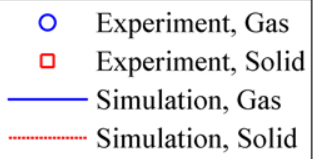

Figure 15. Streamwise velocity profiles for $V_{f l}=1.3 V_{m f}$.

(a) Mean velocity and (b) fluctuating velocity. [Color figure can be viewed in the online issue, which is available at wileyonlinelibrary.com.]

standard deviation in the mean velocity, turbulent kinetic energy, and granular temperature-reached steady statistics in the region where experimental measurements were made. The time average for these quantities was calculated from $t=1$ to $t=30 \mathrm{~s}$ at intervals of $0.1 \mathrm{~s}$. To account for the contribution of unsteadiness in the mean velocities to the gas and particle fluctuations as measured in the experiment, the standard deviation with time in the mean streamwise velocities $\left(v_{\text {g,mean }}^{\prime}, v_{\text {s,mean }}^{\prime}\right)$ were added to the corresponding gas turbulence and granular temperature contributions. The role of such a contribution to velocity fluctuations arising from the large-scale motion induced by the bubbling emulsion phase has been noted in the experiments at high fluidization rates (Rangarajan D, Mychkovsky AG, Curtis JS, Ceccio SL. Effect of emulsion fluidization state on the fluctuations in gas and particle velocities inside the plume of a gas jet penetrating a fluidized bed. Powder Technol. 2011; submitted).

$$
v_{\mathrm{g}, \text { total }}^{\prime}=v_{\mathrm{g}}^{\prime}+v_{\mathrm{g}, \text { mean }}^{\prime}
$$

$$
v_{\mathrm{s}, \text { total }}^{\prime}=v_{s}^{\prime}+v_{\mathrm{s}, \text { mean }}^{\prime}
$$

Figures 12-16 show results of the continuum model simulations for the gas and particle mean and fluctuating velocity at heights $y=0.07,0.1$, and $0.13 \mathrm{~m}$. It must be noted that the unsteady mean velocity contribution can be a significant portion of the total fluctuations at higher fluidization cases as summarized in Table 5. In general, there is good match between the simulation and the experiment for both phases with regard to the mean velocity and fluctuations. Deviations from experiment in the predicted centerline gas velocity at $y=0.07 \mathrm{~m}$ for $V_{f l}=0.7 V_{m f}$ and $V_{m f}$, and the predicted profile spread at $V_{f l}=0,0.7 V_{m f}$ and $1.5 V_{m f}$ can be noted. The shape of the gas fluctuation profiles show deviation at high fluidization rates. To visualize the performance of the continuum model in capturing the bulk flow features associated with increasing fluidization velocity as observed in the experiment, that is, the velocity half-width $\left(x_{1 / 2}\right)$, centerline mean streamwise velocity, and centerline streamwise fluctuating 

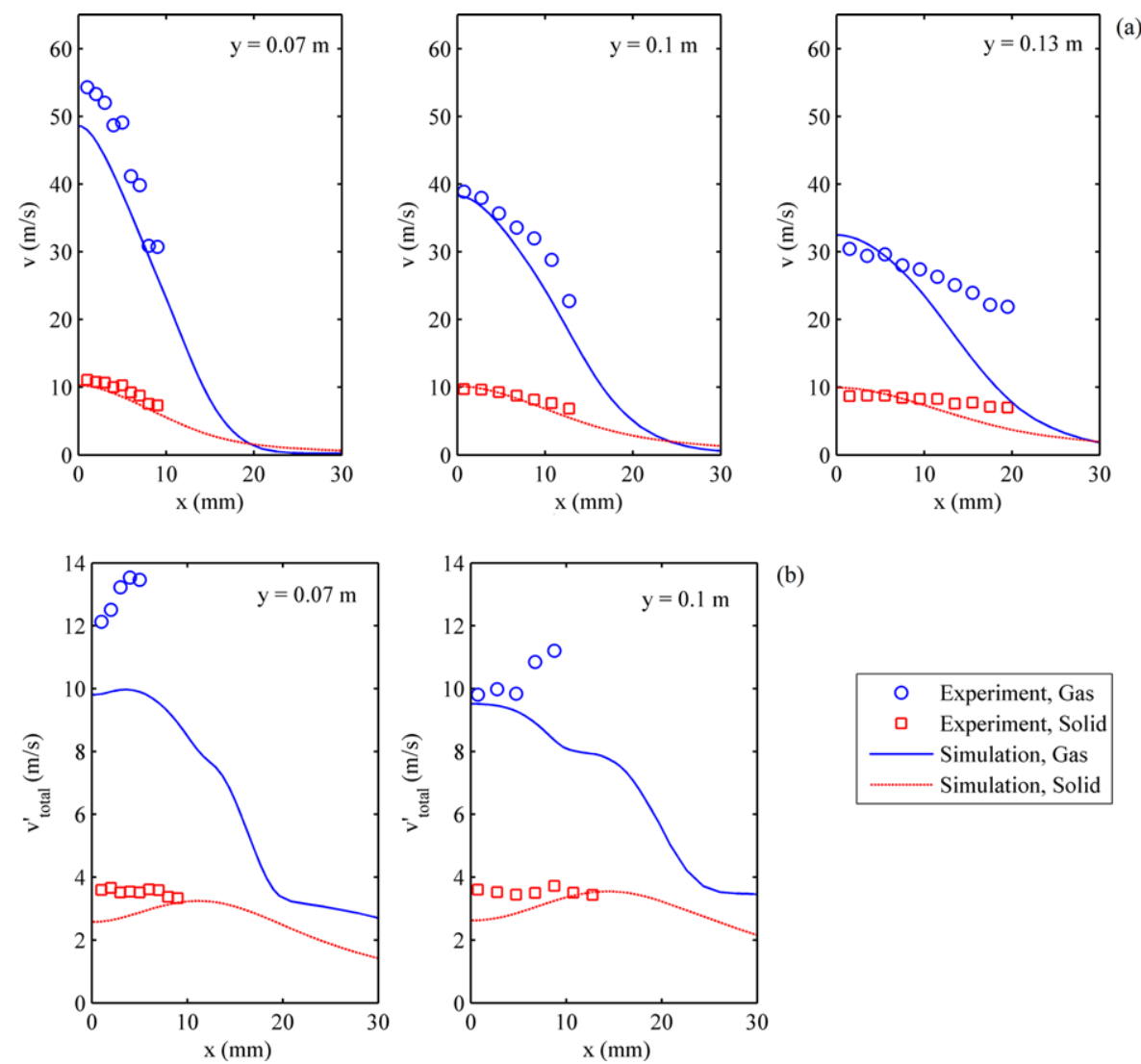

(b)

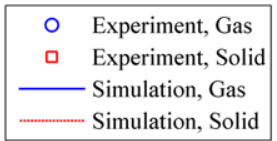

Figure 16. Streamwise velocity profiles for $V_{f l}=1.5 V_{m f}$

(a) Mean velocity and (b) fluctuating velocity. [Color figure can be viewed in the online issue, which is available at wileyonlinelibrary.com.]

velocity are plotted against the level of fluidization at a height $y=0.1 \mathrm{~m}$ (Figures 17). The velocity half-width for each phase is defined as the distance in the $x$-direction, where the velocity is half the centerline velocity at the given height $y$. It can be seen that the simulation is able to predict most of the qualitative behavior seen in the experiment. The centerline gas velocity decreases from single-phase to spouted bed, after which both the gas and particle centerline velocities tend to stay the same with increase in fluidization velocity (Figure 18). There is a decrease in gas turbulence from single-phase to spouted bed case and an increasing trend in both gas and particle fluctuations with increasing fluidization velocity (Figure 19). The main deviation in the qualitative behavior with respect to the fluidization ratio is seen in the model predictions of velocity half-widths for gas and particles. The simulation is not able to capture the increase in gas and particle velocity half-widths with increase in fluidization rate as observed in the experiment (Figure 17).

Table 5. Contribution of Unsteady Mean Velocity to the Total Fluctuations along the Centerline at $y=0.1 \mathrm{~m}$.

\begin{tabular}{lll}
\hline & \multicolumn{2}{c}{$\frac{v_{\text {maan }}^{\prime}}{v_{\text {total }}^{\prime}} * 100$} \\
\cline { 2 - 3 } $\mathrm{V}_{\mathrm{fl}} / \mathrm{V}_{\mathrm{mf}}$ & $\mathrm{Gas}$ & Solid \\
\hline 0.7 & 29 & 21 \\
1 & 42 & 24 \\
1.3 & 53 & 35 \\
1.5 & 47 & 23 \\
\hline
\end{tabular}

In such a complicated system, it is difficult to quantitatively estimate the reason for any mismatches between experiments and model predictions. Experimental repeatability tests estimate uncertainty in the measurements to be less than 15\% (Rangarajan D, Mychkovsky AG, Curtis JS, Ceccio SL. Effect of emulsion fluidization state on the fluctuations in gas and particle velocities inside the plume of a gas

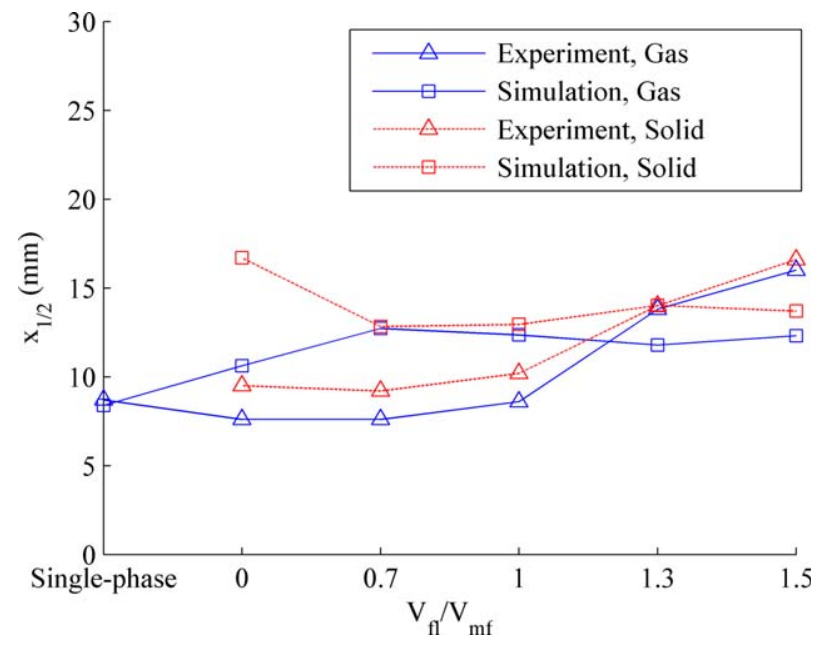

Figure 17. Effect of increasing fluidization velocity on velocity half-widths at $\boldsymbol{y}=0.1 \mathrm{~m}$.

[Color figure can be viewed in the online issue, which is available at wileyonlinelibrary.com.] 
jet penetrating a fluidized bed. Powder Technol. 2011; submitted). It is likely that the deviation in centerline velocities at a low height of $y=0.07 \mathrm{~m}$ is because of some difference caused by the round pipe in the experiment which has been neglected in the simulation. The electrostatic effects between the bounding walls and particles responsible for the inward sloping top surface at $V_{f l}=0$ (Figure 6a), might be causing the sharper velocity profile decay observed in experiment. Since the dynamic instabilities in mean quantities play a significant role in the fluctuating velocity at high fluidization rates (Table 5), it is possible that the deviation in the shape of gas fluctuations is because the sources of fluctuations in the experiment, which are physical, are not precisely captured by the simulation, in which the sources of fluctuations are numerical. The addition of standard deviation in mean velocity to intrinsic turbulence is not entirely warranted, but a more rigorous approach would require deterministic turbulence models which would be computationally very expensive. The narrower spread in the velocity profiles at high fluidization rates obtained in simulation could be because of an insufficient description of the empirically based closure model for frictional stress.

\section{Conclusions}

A turbulent, frictional continuum model has been validated against two-phase mean and fluctuating velocity experimental data inside the jet plume region of a bubbling fluidized bed with a high-speed vertical jet injection. The descriptions for closure were selected from well-established relations wherever possible, and the main uncertainties were identified and determined by benchmarking against specific experimental measurements. In general, the continuum model shows good agreement with the two-phase mean and fluctuating velocities and is able to predict the experimental trends with increasing fluidization velocity reasonably well. Main discrepancies between model prediction and experiment are noted in the spread of velocity profiles and the shape of gas fluctuation profiles at high fluidization rates. Possible reasons for the mismatch are discussed.

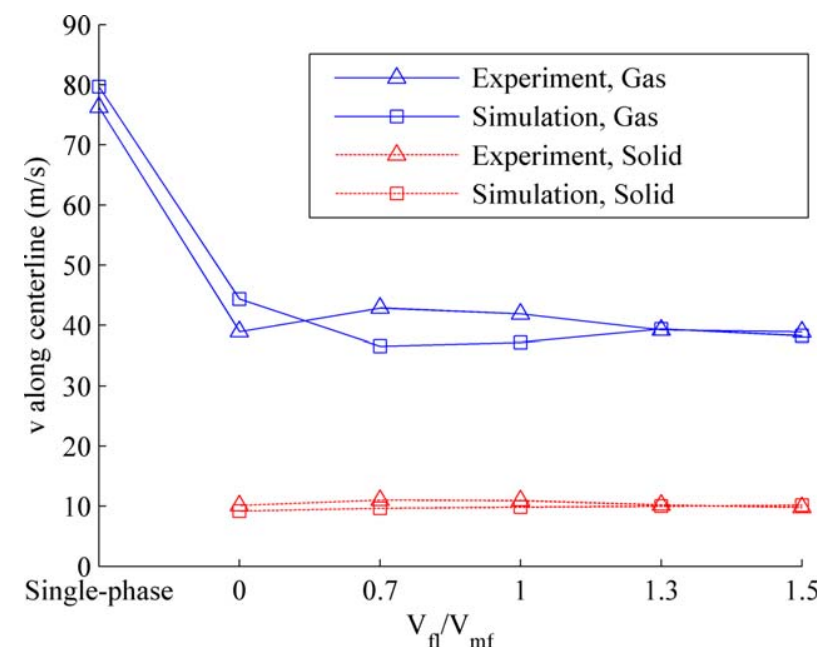

Figure 18. Effect of increasing fluidization velocity on mean streamwise velocity along the centerline at $y=0.1 \mathrm{~m}$.

[Color figure can be viewed in the online issue, which is available at wileyonlinelibrary.com.]

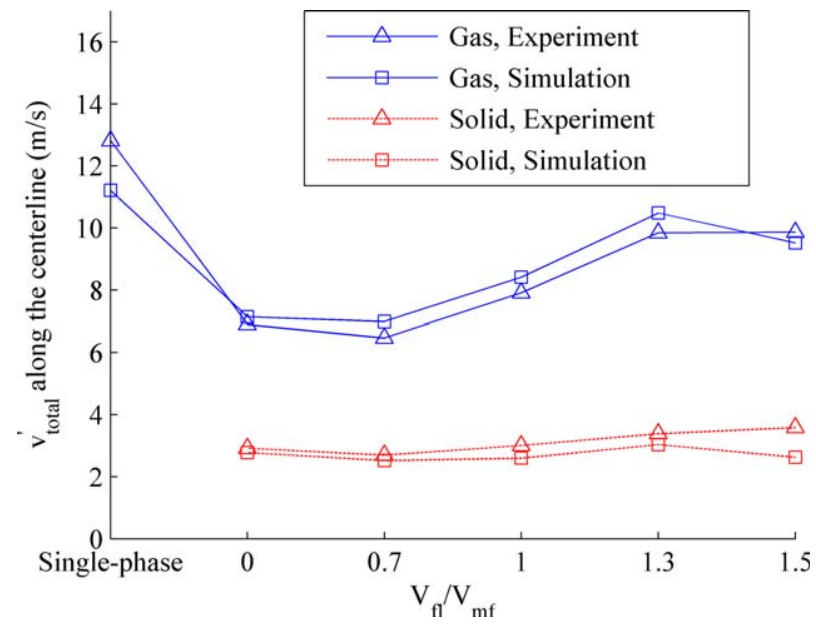

Figure 19. Effect of increasing fluidization velocity on the streamwise fluctuating velocity along the centerline at $y=0.1 \mathrm{~m}$.

[Color figure can be viewed in the online issue, which is available at wileyonlinelibrary.com.]

\section{Acknowledgments}

The funding for this work was sponsored by the Department of Energy's Office of Fossil Energy's University Research Program under project number DE-NT0007649. The authors acknowledge the University of Florida HighPerformance Computing Center for providing computational resources and support that have contributed to the research results reported within this article (URL: http://hpc.ufl.edu).

\section{Notation}

$$
\begin{aligned}
& C_{1 \varepsilon}, C_{2 \varepsilon}, C_{3 \varepsilon}, C_{\mu}, \sigma_{k}, \sigma_{\varepsilon}=\text { constants in k-epsilon gas turbulence model } \\
& C_{\mathrm{D}}=\text { drag coefficient } \\
& D_{\mathrm{j}}=\text { inlet jet diameter, } \mathrm{L} \\
& d_{\mathrm{p}}=\text { particle diameter, } \mathrm{L} \\
& e=\text { particle-particle restitution coefficient } \\
& e_{\mathrm{w}}=\text { particle-wall restitution coefficient } \\
& \underline{F}_{\mathrm{D}}=\underset{\mathrm{ML}^{-2} \mathrm{~T}^{-2}}{\operatorname{interphas}} \text { drag force per unit volume, } \\
& F r=\text { constant in frictional pressure expression, } \\
& \mathrm{ML}^{-1} \mathrm{~T}^{-2} \\
& g=\text { acceleration due to gravity, } \mathrm{LT}^{-2} \\
& g_{0}=\text { radial distribution function at contact } \\
& \underline{I}=\text { identity tensor } \\
& \overline{\overline{J_{\mathrm{s}}}}=\text { granular energy dissipation due to inelastic } \\
& \text { collisions, } \mathrm{L}^{2} \mathrm{~T}^{-3} \\
& k=\text { gas phase turbulent kinetic energy, } \mathrm{L}^{2} \mathrm{~T}^{-2} \\
& L, H, W=\text { column width, height, and thickness, } \mathrm{L} \\
& L_{\mathrm{p}}=\text { inlet pipe length, } \mathrm{L} \\
& M W=\text { molecular weight of gas } \\
& p=\text { pressure, } \mathrm{ML}^{-1} \mathrm{~T}^{-2} \\
& r=\text { constant in frictional pressure expression } \\
& R e_{\mathrm{p}}=\text { particle Reynolds number } \\
& s=\text { constant in frictional pressure expression } \\
& \underline{S}_{\mathrm{s}}=\text { solid rate of strain tensor, } \mathrm{T}^{-1} \\
& t=\text { time, } \mathrm{T} \\
& T=\text { temperature of gas, } \mathrm{K} \\
& u=\text { velocity, } \mathrm{LT}^{-1} \\
& \underline{u}^{\top}=\text { fluctuating velocity (turbulent contribution), } \\
& \mathrm{LT}^{-1} \\
& v=\text { vertical component of mean velocity, } \mathrm{LT}^{-1} \\
& v^{\prime}=\text { vertical component of fluctuating velocity } \\
& v_{\text {mean }}^{\prime}=\text { vertical component of fluctuating velocity } \\
& \text { (mean contribution), } \mathrm{LT}^{-1}
\end{aligned}
$$


$v_{\text {total }}^{\prime}=$ vertical component of fluctuating velocity (mean+turbulent contributions), $\mathrm{LT}^{-1}$

$V_{f l}=$ fluidization velocity, $\mathrm{LT}^{-1}$

$V_{j}=$ vertical inlet jet velocity, $\mathrm{LT}^{-1}$

$V_{m f}=$ minimum fluidization velocity, $\mathrm{LT}^{-1}$

$x, y=$ horizontal and vertical coordinates, $\mathrm{L}$

$x_{1 / 2}=x$ length where the streamwise velocity becomes half centerline velocity, L

\section{Greek letters}

$$
\begin{aligned}
\dot{\alpha} & =\text { constant in granular theory } \\
\beta & =\text { gas-solids drag force coefficient, } \mathrm{ML}^{-3} \mathrm{~T}^{-1} \\
\delta & =\text { angle of internal friction } \\
\Delta P / \Delta H= & \text { pressure drop per unit height, } \mathrm{ML}^{-2} \mathrm{~T}^{-2} \\
\delta_{\mathrm{w}}= & \text { angle of wall friction } \\
\varepsilon= & \text { gas turbulent energy dissipation, } \mathrm{L}^{2} \mathrm{~T}^{-3} \\
\varepsilon_{\mathrm{m}}= & \text { volume fraction of phase } m \\
\eta= & \text { constant depending on particle restitution } \\
& \text { coefficient } \\
\theta= & \text { granular temperature, } \mathrm{L}^{2} \mathrm{~T}^{-2} \\
\kappa_{\mathrm{s}}= & \text { solids granular conductivity, } \mathrm{ML}^{-1} \mathrm{~T}^{-1} \\
\mu= & \text { viscosity, } \mathrm{ML}^{-1} \mathrm{~T}^{-1} \\
\pi_{\mathrm{k}}= & \text { turbulence enhancement due to granular } \\
& \text { energy exchange, } \mathrm{ML}^{-1} \mathrm{~T}^{-3} \\
\pi_{\mathrm{k}}{ }^{\mathrm{drag}}= & \text { drag contribution to gas turbulence enhance- } \\
& \text { ment, } \mathrm{ML}^{-1} \mathrm{~T}^{-3} \\
\pi_{\mathrm{k}}{ }^{\text {wake }}= & \text { wake contribution to gas turbulence enhance- } \\
& \text { ment, } \mathrm{ML}^{-1} \mathrm{~T}^{-3} \\
\pi_{\theta}= & \text { granular energy enhancement due to turbu- } \\
& \text { lence exchange, } \mathrm{ML}^{-1} \mathrm{~T}^{-3} \\
\rho= & \text { density, } \mathrm{ML}^{-3} \\
\frac{\sigma}{\tau}= & \text { stress tensor, } \mathrm{ML}^{-1} \mathrm{~T}^{-2} \\
\varphi= & \text { shear stress tensor, } \mathrm{ML}^{-1} \mathrm{~T}^{-2} \\
\varphi & \text { specularity coefficient }
\end{aligned}
$$

\section{Subscript}

$$
\begin{aligned}
\mathrm{g} & =\text { gas phase } \\
\mathrm{j} & =\text { inlet jet conditions } \\
\mathrm{s} & =\text { solid phase }
\end{aligned}
$$

\section{Superscript}

$$
\begin{aligned}
\mathrm{f} & =\text { frictional } \\
\mathrm{kc} & =\text { kinetic and collisional } \\
\max & =\text { maximum packing } \\
\min & =\text { intermediate packing }
\end{aligned}
$$

\section{Literature Cited}

1. Roach PE. The penetration of jets into fluidized-beds. Fluid Dyn Res. 1993;11:197-216.

2. Merry JMD. Penetration of vertical jets into fluidized-beds. AIChE J. 1975;21:507-510.

3. Curtis JS, van Wachem B. Modeling particle-laden flows: a research outlook. AIChE J. 2004;50:2638-2645.

4. van Wachem BGM, Almstedt AE. Methods for multiphase computational fluid dynamics. Chem Eng J. 2003;96:81-98.

5. van Wachem BGM, Schouten JC, van den Bleek CM, Krishna R, Sinclair JL. Comparative analysis of CFD models of dense gas-solid systems. AIChE J. 2001;47:1035-1051.

6. Lindborg H, Lysberg M, Jakobsen HA. Practical validation of the two-fluid model applied to dense gas-solid flows in fluidized beds. Chem Eng Sci. 2007;62:5854-5869.

7. Acosta-Iborra A, Sobrino C, Hernandez-Jimenez F, de Vega M. Experimental and computational study on the bubble behavior in a 3-D fluidized bed. Chem Eng Sci. 2011;66:3499-3512.

8. Makkawi Y, Wright PC, Ocone R. The effect of friction and interparticle cohesive forces on the hydrodynamics of gas-solid flow: a comparative analysis of theoretical predictions and experiments. Powder Technol. 2006;163:69-79.

9. Johansson K, van Wachem BGM, Almstedt AE. Experimental validation of CFD models for fluidized beds: influence of particle stress models, gas phase compressibility and air inflow models. Chem Eng Sci. 2006;61:1705-1717.

10. Santos KG, Murata VV, Barrozo MAS. Three-dimensional computational fluid dynamics modelling of spouted bed. Can J Chem Eng. 2009;87:211-219.
11. Bettega R, Felkl de Almeida AR, Correa RG, Freire JT. CFD modelling of a semi-cylindrical spouted bed: numerical simulation and experimental verification. Can J Chem Eng. 2009;87:177-184.

12. Gryczka O, Heinrich S, Deen NG, Annalan MVS, Kuipers JAM, Jacob M, Moerl L. Characterization and CFD-modeling of the hydrodynamics of a prismatic spouted bed apparatus. Chem Eng Sci. 2009;64:3352-3375.

13. Hosseini SH, Ahmadi G, Razavi BS, Zhong W. Computational fluid dynamic simulation of hydrodynamic behavior in a two-dimensional conical spouted bed. Energy Fuels. 2010;24:6086-6098.

14. Zhonghua W, Mujumdar AS. CFD modeling of the gas-particle flow behavior in spouted beds. Powder Technol. 2008;183:260-272.

15. Wang Z, Bi HT, Lim CJ. CFD simulation of spouted beds using a pressure source term. Ind Eng Chem Res. 2010;49:5053-5060.

16. Duarte CR, Olazar M, Murata VV, Barrozo MAS. Numerical simulation and experimental study of fluid-particle flows in a spouted bed. Powder Technol. 2009;188:195-205.

17. Huilin L, Yurong H, Wentie L, Ding J, Gidaspow D, Bouillard J. Computer simulations of gas-solid flow in spouted beds using kinetic-frictional stress model of granular flow. Chem Eng Sci. 2004;59:865-878.

18. Boemer A, Qi H, Renz U. Eulerian simulation of bubble formation at a jet in a two-dimensional fluidized bed. Int J Multiphase Flow. 1997;23:927-944.

19. Patil DJ, Annaland MV, Kuipers JAM. Critical comparison of hydrodynamic models for gas-solid fluidized beds-Part I: bubbling gassolid fluidized beds operated with a jet. Chem Eng Sci. 2005;60:5772.

20. Li T, Pougatch K, Salcudean M, Grecov D. Numerical simulation of horizontal jet penetration in a three-dimensional fluidized bed. Powder Technol. 2008;184:89-99.

21. Li T, Pougatch K, Salcudean M, Grecov D. Numerical simulation of single and multiple gas jets in bubbling fluidized beds. Chem Eng Sci. 2009;64:4884-4898.

22. Ettehadieh B, Gidaspow D, Lyczkowski RW. Hydrodynamics of fluidization in a semicircular bed with a jet. AIChE J. 1984;30:529536.

23. Mychkovsky AG, Ceccio SL. LDV measurements and analysis of gas and particulate phase velocity profiles in a vertical jet plume in a 2D bubbling fluidized bed Part III: the effect of fluidization. Powder Technol. 2012;220:37-46.

24. Anderson TB, Jackson R. A fluid mechanical description of fluidized beds. Ind Eng Chem Fundam. 1967;6:527-539.

25. Wen CY, Yu YH. Mechanics of fluidization. Chem Eng Prog Symposium Series. 1966;62:100-111.

26. Srivastava A, Sundaresan S. Analysis of a fractional-kinetic model for gas-particle flow. Powder Technol. 2003;129:72-85.

27. Rao A, Curtis JS, Hancock BC, Wassgren C. Numerical simulation of dilute turbulent gas-particle flow with turbulence modulation. AIChE J. 2012;58:1381-1396.

28. Bolio EJ, Yasuna JA, Sinclair JL. Dilute turbulent gas-solid flow in risers with particle-particle interactions. AIChE J. 1995;41:13751388.

29. Benyahia S, Syamlal M, O'Brien TJ. Study of the ability of multiphase continuum models to predict core-annulus flow. AIChE J. 2007;53:2549-2568.

30. Benyahia S, Syamlal M, O'Brien TJ. Evaluation of boundary conditions used to model dilute, turbulent gas/solids flows in a pipe. Powder Technol. 2005;156:62-72.

31. Simonin O. Continuum Modeling of Dispersed Two-Phase Flows in Combustion and Turbulence in Two-Phase Flows. Von Karman Institute of Fluid Dynamics Lecture Series, Volume 29, 1996.

32. Lun CKK, Savage SB, Jeffrey DJ, Chepurniy N. Kinetic theories for granular flow-inelastic particles in couette-flow and slightly inelastic particles in a general flowfield. J Fluid Mech. 1984;140:223-256.

33. Agrawal K, Loezos PN, Syamlal M, Sundaresan S. The role of meso-scale structures in rapid gas-solid flows. $J$ Fluid Mech. 2001;445:151-185.

34. Reuge N, Cadoret L, Coufort-Saudejaud C, Pannala S, Syamlal M, Caussat B. Multifluid Eulerian modeling of dense gas-solids fluidized bed hydrodynamics: influence of the dissipation parameters. Chem Eng Sci. 2008;63:5540-5551.

35. Carnahan NF, Starling KE. Equation of state for nonattracting rigid spheres. J Chem Phys. 1969;51:635-636.

36. Benyahia S. Validation study of two continuum granular frictional flow theories. Ind Eng Chem Res. 2008;47:8926-8932. 
37. Patil DJ, Annaland AV, Kuipers JAM. Critical comparison of hydrodynamic models for gas-solid fluidized beds-Part II: freely bubbling gas-solid fluidized beds. Chem Eng Sci. 2005;60:73-84.

38. Passalacqua A, Marmo L. A critical comparison of frictional stress models applied to the simulation of bubbling fluidized beds. Chem Eng Sci. 2009;64:2795-2806.

39. Syamlal M, Rogers W, O'Brien TJ. MFIX Documentation: Theory Guide. U.S. Department of Energy, WV, 1993.

40. Johnson PC, Nott P, Jackson R. Frictional collisional equations of motion for particulate flows and their application to chutes. J Fluid Mech. 1990;210:501-535.

41. Schaeffer DG. Instability in the evolution equations describing incompressible granular flow. J Differ Equations. 1987;66:19-50.

42. Savage SB. Analyses of slow high-concentration flows of granular materials. J Fluid Mech. 1998;377:1-26.

43. Louge MY, Mastorakos E, Jenkins JT. The role of particle collisions in pneumatic transport. J Fluid Mech. 1991;231:345-359.

44. Crowe CT. On models for turbulence modulation in fluid-particle flows. Int J Multiphase Flow. 2000;26:719-727.

45. Sinclair J, Mallo T. Describing particle-turbulence interaction in a two-fluid modeling framework. ASME Fluids Engineering Division Summer Meeting. New York, NY: ASME Press, 1998:7-12.

46. Koch DL, Sangani AS. Particle pressure and marginal stability limits for a homogeneous monodisperse gas-fluidized bed: kinetic theory and numerical simulations. J Fluid Mech. 1999;400:229-263.

47. Johnson PC, Jackson R. Frictional collisional constitutive relations for antigranulocytes-materials, with application to plane shearing. J Fluid Mech. 1987;176:67-93.

48. Benyahia S, Syamlal M, O'Brien TJ. Summary of MFIX Equations Version 2005-4, 2006. https://mfix.netl.doe.gov/documentation/MFIXEquations2005-4-4.pdf.
49. Mychkovsky AG. LDV Measurements and Analysis of Gas and Particulate Phase Velocity Profiles in a Vertical Jet Plume in a 2D Bubbling Fluidized Bed. PhD, University of Michigan, Ann Arbor, 2010.

50. Mychkovsky A, Rangarajan D, Ceccio S. LDV measurements and analysis of gas and particulate phase velocity profiles in a vertical jet plume in a $2 \mathrm{D}$ bubbling fluidized bed: Part I: a two-phase LDV measurement technique. Powder Technol. 2012;220:55-62.

51. Mychkovsky AG, Ceccio SL. LDV measurements and analysis of gas and particulate phase velocity profiles in a vertical jet plume in a 2D bubbling fluidized bed Part II: mass and momentum transport. Powder Technol. 2012;220:47-54.

52. Dan S, Jianzhi W, Huilin L, Yunhua Z, Juhui C, Gidaspow D, Ming C. Numerical simulation of gas-particle flow with a second-order moment method in bubbling fluidized beds. Powder Technol. 2010;199:213-225.

53. Dan S, Shuyan W, Huilin L, Zhiheng S, Xiang L, Shuai W, Yunhua $\mathrm{Z}$, Lixin W. A second-order moment method of dense gas-solid flow for bubbling fluidization. Chem Eng Sci. 2009;64:5013-5027.

54. Gutmark E, Wygnanski I. Planar turbulent jet. J Fluid Mech. 1976;73:465-495.

55. Jones EN. An Experimental Investigation of Particle Size Distribution Effects in Gas-Solid Flow. PhD, Purdue University, Purdue, IN, 2001.

56. Lun CKK. Numerical simulation of dilute turbulent gas-solid flows. Int J Multiphase Flow. 2000;26:1707-1736.

57. Gore RA, Crowe CT. Effect of particle-size on modulating turbulent intensity. Int J Multiphase Flow. 1989;15:279-285.

58. Rangarajan D, Curtis JS. The effect of spanwise width on rectangular jets with sidewalls. J Fluids Eng. 2012;134:031202.

Manuscript received Aug. 2, 2012, and revision received Nov. 27, 2012. 